\title{
Spring bloom onset in the Nordic Seas
}

\author{
Alexandre Mignot ${ }^{1}$, Raffaele Ferrari $^{1}$, and Kjell Arne Mork ${ }^{2,3}$ \\ ${ }^{1}$ Massachusetts Institute of Technology, Cambridge, MA, USA \\ ${ }^{2}$ Institute of Marine Research, Bergen, Norway \\ ${ }^{3}$ Bjerknes Centre for Climate Research, Bergen, Norway \\ Correspondence to: Alexandre Mignot (mignot@mit.edu)
}

Received: 31 July 2015 - Published in Biogeosciences Discuss.: 21 August 2015

Revised: 4 May 2016 - Accepted: 9 May 2016 - Published: 15 June 2016

\begin{abstract}
The North Atlantic spring bloom is a massive annual growth event of marine phytoplankton, tiny free-floating algae that form the base of the ocean's food web and generates a large fraction of the global primary production of organic matter. The conditions that trigger the onset of the spring bloom in the Nordic Seas, at the northern edge of the North Atlantic, are studied using in situ data from six biooptical floats released north of the Arctic Circle. It is often assumed that spring blooms start as soon as phytoplankton cells daily irradiance is sufficiently abundant that division rates exceed losses. The bio-optical float data instead suggest the tantalizing hypothesis that Nordic Seas blooms start when the photoperiod, the number of daily light hours experienced by phytoplankton, exceeds a critical value, independently of division rates. The photoperiod trigger may have developed at high latitudes where photosynthesis is impossible during polar nights and phytoplankton enters into a dormant stage in winter. While the first accumulation of biomass recorded by the bio-optical floats is consistent with the photoperiod hypothesis, it is possible that some biomass accumulation started before the critical photoperiod but at levels too low to be detected by the fluorometers. More precise observations are needed to test the photoperiod hypothesis.
\end{abstract}

\section{Introduction}

The Nordic Seas (Norwegian, Greenland, and Iceland Seas) experience some of the largest carbon dioxide $\left(\mathrm{CO}_{2}\right)$ fluxes anywhere in the ocean resulting in a carbon uptake of 20 $85 \mathrm{~g} \mathrm{C} \mathrm{m}^{-2} \mathrm{yr}^{-1}$ (Takahashi et al., 2002). In the Greenland Sea it has been estimated that one third of the annual carbon uptake is driven by export production from biological activity, while the rest is the result of $\mathrm{CO}_{2}$ dissolution in cold waters that sink into the abyss (Skjelvan et al., 2005). Most of the biological production occurs during ephemeral spring blooms lasting only a few weeks. A good understanding of the conditions that trigger these blooms is a prerequisite to quantify and model the carbon budget of the Nordic Seas.

In winter, phytoplankton populations decay because losses from respiration, grazing, and viral infections exceed growth. Blooms develop in spring when division rates increase and/or loss rates decrease. Phytoplankton division rates increase with abundance of nutrients and light. At high latitudes, nutrients are plentiful in winter, because the strong upper ocean mixing generated by winds and cooling brings deep nutrients to the surface. Thus light appears to be the limiting factor for winter growth in the sub-polar gyres, as argued in the seminal works of Gran and Braarud (1935), Riley (1946) and Sverdrup (1953). However, it was soon noted that the surface light levels in winter are sufficient for photosynthesis growth even at these latitudes. Thus, the light limitation has been attributed to mixing that keeps phytoplankton cells away from the well-lit surface for long periods of time. Sverdrup (1953) formalized this view and suggested that blooms develop when mixing weakens at the end of winter and phytoplankton spends more time close to the surface to receive enough light to grow in spite of losses. More recently, Behrenfeld et al. $(2013,2014)$ pointed out that blooms can alternatively develop when a disturbance in the predator-prey balance reduces loss rates below division rates. The disturbance may be initiated by winter mixing that dilutes both phytoplankton and herbivores reducing their encounter rates and hence the grazing rates (Behrenfeld, 2010). It may also be triggered by an improvement in growth conditions, through increase in 
light exposure or nutrient availability that causes the division rates to accelerate and to outcompete the grazing rates.

These ideas dominate thinking about bloom dynamics, but they may not be as relevant to understand blooms in the Nordic Seas. At these extreme latitudes, insolation drops dramatically in winter. North of the Arctic Circle, no light is received at the ocean surface during polar nights. Phytoplankton growth is simply impossible for days to weeks, depending on the latitude, regardless of mixing levels. It is therefore natural to ask how phytoplankton populations survive such harsh conditions and what triggers their resurgence in spring.

In this work, we study the development of blooms in the Nordic Seas using in situ profiles of phytoplankton from six bio-optical floats released north of the Arctic Circle. The floats were instrumented with miniaturized bio-optical sensors, which measure chlorophyll concentrations in the upper kilometre of the ocean for 1 to 2 years. The data suggest that at these high latitudes, one of two possible scenarios explains the onset of the Nordic Seas blooms observed by the floats: the critical photoperiod hypothesis or the critical depth hypothesis.

The paper is organized as follows. We introduce the data sets used in the study in Sect. 2 . Section 3 provides a preliminary analysis of the data with the conclusion that two possible interpretations can explain the onset of the Nordic Seas blooms. In Sect. 4, we develop the theoretical framework to test the two hypotheses. This framework is then used in Sect. 5 to interpret the data. Finally, Sect. 6 summarizes and discusses the results.

\section{Data}

\subsection{Floats located north of the Arctic Circle}

Our results are based on measurements collected with six bio-optical profiling floats deployed in the Nordic Seas, by the Institute of Marine Research in Norway (see Fig. 1 and Table 1). Three floats were deployed in 2010 (IMR1, IMR2 and IMR3) and three floats were deployed in 2014 (IMR4, IMR5, and IMR6). The Argo float data were downloaded from the Argo Global Data Assembly Centre (Argo GDAC) in France (Carval et al., 2015). The three floats deployed in 2010 were in the water for 2 years and returned observations of six spring blooms. The three floats deployed in 2014 are still operating and sampled the 2014-2015 spring bloom.

We consider measurements made by the floats IMR1, IMR2 and IMR3 from September 2010 to June 2011 and from September 2011 to June 2012, time periods long enough to capture the onset of the spring blooms - the float IMR3 was deployed in November 2010 and hence the analysis starts in November of that year. Measurements from floats IMR4, IMR5 and IMR6 span the interval from September 2014 to June 2015.

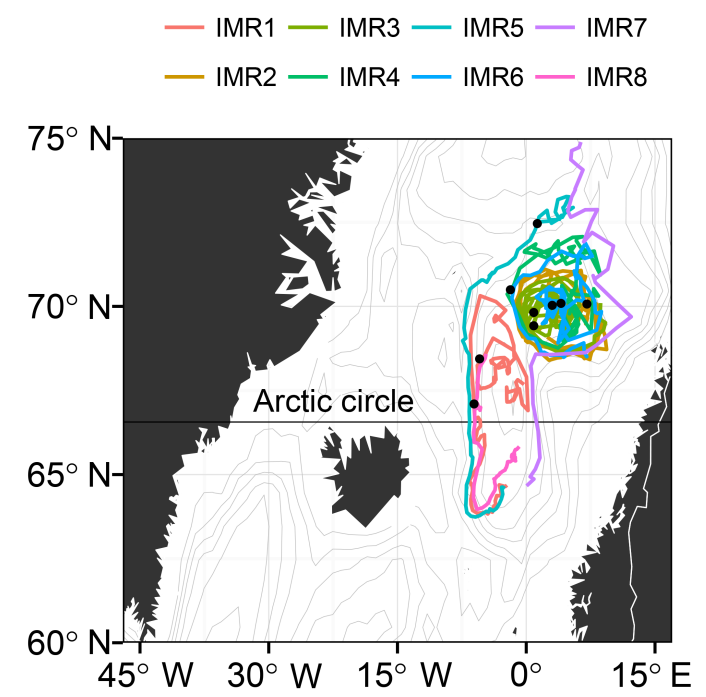

Figure 1. Trajectory of the floats used in the study. The black symbols show the location of the floats which profiled North of the Arctic Circle (i.e., IMR1, IMR2, IMR3, IMR4, IMR5 and IMR6) at $t_{\mathrm{E}}$.

\subsection{Floats located south of the Arctic Circle}

Two bio-optical floats (IMR7 and IMR8), deployed in November 2013 and July 2014 respectively, observed a spring bloom south of the Arctic Circle. These floats are used to compare blooms north and south of Arctic Circle and better illustrate the effect of complete darkness on the phytoplankton dynamics. The IMR7 and IMR8 float data were also downloaded from the Argo GDAC in France.

\subsection{Floats instrumentation and calibration}

All floats were APEX float profilers, equipped with a WET Labs ECO FLNTU comprising a chlorophyll fluorometer, and a backscattering sensor at $700 \mathrm{~nm}$. The IMR1-3 and IMR7 floats included a SEABIRD dissolved oxygen sensor while the IMR4-6 and IMR8 floats included an Aanderaa optode $\left[\mathrm{O}_{2}\right]$ sensor.

The IMR1-3 floats nominal mission included CTD and optical profiles from $1000 \mathrm{~m}$ to the surface. The sampling resolution was $25 \mathrm{~m}$ from 1000 to $350 \mathrm{~m}, 10 \mathrm{~m}$ from 350 to $100 \mathrm{~m}$, and $5 \mathrm{~m}$ from $100 \mathrm{~m}$ to the surface. The IMR4-8 floats nominal mission included CTD and optical profiles from $2000 \mathrm{~m}$ to the surface. The sampling resolution was $50 \mathrm{~m}$ from 2000 to $1000 \mathrm{~m}, 20 \mathrm{~m}$ from 1000 to $500 \mathrm{~m}, 10 \mathrm{~m}$ from 500 to $200 \mathrm{~m}$, and $5 \mathrm{~m}$ from $200 \mathrm{~m}$ to the surface. The upward casts were repeated every 5 or 10 days. The floats typically emerged from the sea around midnight, but, occasionally, they reached the surface in the morning or in the afternoon.

The CTD data were quality-controlled using the standard Argo protocol (Wong et al., 2010). The fluorescence raw signals (counts) were transformed into $\mathrm{Chl} a$ concentration, 
Table 1. Relevant information concerning the nine bio-optical profiling floats used in this study.

\begin{tabular}{|c|c|c|c|c|}
\hline Float & $\begin{array}{l}\text { wmo } \\
\text { number }\end{array}$ & $\begin{array}{l}\text { Deployment } \\
\text { location }\end{array}$ & $\begin{array}{l}\text { Deployment } \\
\text { date }\end{array}$ & $\begin{array}{l}\text { Sensor failure } \\
\text { date }\end{array}$ \\
\hline IMR1 & 6900796 & $0.25^{\circ} \mathrm{W}, 67.68^{\circ} \mathrm{N}$ & 30 May 2010 & $\begin{array}{l}\text { Optical sensors: } 31 \text { Oct } 2012 \\
\text { CTD: } 19 \text { Jan } 2013\end{array}$ \\
\hline IMR2 & 6900798 & $2.43^{\circ} \mathrm{E}, 69.09^{\circ} \mathrm{N}$ & 02 Jul 2010 & $\begin{array}{l}\text { Optical sensors: } 01 \text { Nov } 2012 \\
\text { CTD is still operational }\end{array}$ \\
\hline IMR3 & 6900799 & $6.01^{\circ} \mathrm{E}, 70.03^{\circ} \mathrm{N}$ & 06 Nov 2010 & $\begin{array}{l}\text { Optical sensors: } 31 \text { Oct } 2012 \\
\text { CTD: } 20 \text { Sept } 2013\end{array}$ \\
\hline IMR4 & 6902545 & $7.54^{\circ} \mathrm{E}, 69.27^{\circ} \mathrm{N}$ & 23 Jan 2014 & ongoing \\
\hline IMR5 & 6902549 & $1.40^{\circ} \mathrm{E}, 72.57^{\circ} \mathrm{N}$ & $29 \mathrm{Jul} 2014$ & ongoing \\
\hline IMR6 & 6902550 & $5.90^{\circ} \mathrm{E}, 70.78^{\circ} \mathrm{N}$ & 04 Aug 2014 & ongoing \\
\hline IMR7 & 6902544 & $0.04^{\circ} \mathrm{E}, 64.66^{\circ} \mathrm{N}$ & 16 Nov 2013 & ongoing \\
\hline IMR8 & 6902548 & $4.70^{\circ} \mathrm{W}, 68.58^{\circ} \mathrm{N}$ & $21 \mathrm{Jul} 2014$ & ongoing \\
\hline IMR9 & 6902547 & $7.30^{\circ} \mathrm{E}, 69.13^{\circ} \mathrm{N}$ & 22 Jan 2014 & ongoing \\
\hline
\end{tabular}

[Chl $a$ ], expressed in $\mathrm{mg} \mathrm{m}^{-3}$ via a scale factor and after the nominal instrument-specific dark counts had been subtracted. The manufacturer provides two parameters for converting measured fluorescence counts to estimated $[\mathrm{Chl} a]$ : a nominal instrument-specific dark counts and a scale factor expressed in $\mathrm{mg} \mathrm{m}^{-3}$ relating measured fluorescence minus the dark counts to [Chl $a$ ] .

We tested the accuracy of the scale factor provided by the manufacturer against a slope determined by a regression between the float fluorescence (minus the dark counts) and $[\mathrm{Chl} a]$ estimates from Moderate Resolution Imaging Spectroradiometer (MODIS), a method first proposed by Boss et al. (2008). The satellite [Chl $a$ ] estimates represent a measurement weighted from the surface to the first optical depth. For comparison with MODIS data, float fluorescence measurements were therefore weighted in the same way; i.e :

$\mathrm{fl}_{\mathrm{surf}}=\frac{\int_{-H_{90}}^{0} e^{2 K_{\mathrm{d}}(490) z} \mathrm{fl}(z) \mathrm{d} z}{\int_{-H_{90}}^{0} e^{2 K_{\mathrm{d}}(490) z \mathrm{~d} z}}$,

where $\mathrm{fl}(z)$ is the vertical profile of fluorescence minus the dark counts, $H_{90}$ is the first optical depth, and $K_{\mathrm{d}}(490)$ is the diffuse attenuation coefficient for downwelling irradiance at $490 \mathrm{~nm}$ estimated by MODIS.

We used the 8-day level 3 MODIS composites in $1^{\circ} \times 1^{\circ}$ boxes centred on the float locations for match up data. The MODIS matchups for all floats were used to estimate the regression slopes. These regression coefficients were significantly smaller than those provided by the manufacturers for our fluorometers (see Table 2). The variations in regression slopes for the different floats are likely due to uncertainties in the matchups: we are regressing $1^{\circ} \times 1^{\circ}$ satellite data to pointwise measurements. Thus, we computed the MODISbased correction by averaging over all eight floats and applied a $0.0029 \pm 0.0014 \mathrm{mg} \mathrm{m}^{-3}$ count $^{-1}$ slope to compute chlorophyll from the eight fluorometers. Applying individual regression slope resulted in very different chlorophyll values for each float, a result inconsistent with the fact that the floats sampled the same general region.

The winter backscatter values in the mixed layer were always lower than the values below; possibly because particles below the mixed layer had different composition than those above. Regardless, this prevented us from using these data to investigate the phytoplankton dynamics.

\subsection{Atmospheric and solar variables}

In our analysis, we need estimates of the heat and freshwater fluxes that drive upper ocean turbulence and the photosynthetically active radiation (PAR). The hourly net atmospheric heat fluxes $\left(Q_{0}\right.$ in $\left.\mathrm{W} \mathrm{m}^{-2}\right)$ were taken from the ECMWF ERA-interim reanalysis (Dee et al., 2011). We ignored the freshwater fluxes and winds that are a minor contributor to upper ocean turbulence in the winter North Atlantic (Ferrari et al., 2014). Time series of the heat fluxes along the float trajectories were then generated by averaging the daily ERA-interim values in one by one degree bins around the float daily positions.

The clear sky instantaneous PAR just beneath the sea surface in $\mu$ mol photons $\mathrm{m}^{-2} \mathrm{~s}^{-1}$, iPAR clear $(0, t)$, was calculated using the Gregg and Carder (1990) solar irradiance model for a free-cloud sky. The reduction in PAR due to clouds was estimated with the formulation of Budyko et al. (1964):

$\operatorname{iPAR}(0, t)=\operatorname{iPAR}_{\text {clear }}(0, t)\left(1-0.14 c-0.38 c^{2}\right)$,

where $c$ is the total cloud cover. The total cloud $\operatorname{cover} c$, varying from 1 for an overcast sky to 0 for a clear sky, was taken from ECMWF ERA-interim reanalysis averaged along the float trajectories as described for the heat fluxes. The daily averaged sea surface PAR in mol photons $\mathrm{m}^{-2} \mathrm{~d}^{-1}, \operatorname{PAR}(0)$, was obtained by averaging Eq. (2) over the length of the day. The irradiance model was evaluated with iPAR measure- 
Table 2. Fluorometer scale factors provided by the manufacturer, number of MODIS match-ups, regression slopes determined by a regression through the origin and correlation coefficients between the float fluorescence (minus the dark counts) and MODIS [Chl $a$ ] estimates.

\begin{tabular}{lrrrr}
\hline Float & $\begin{array}{r}\text { Manufacturer } \\
\text { scale factor } \\
\left(\mathrm{mg} \mathrm{m}^{-3} \text { count }^{-1}\right)\end{array}$ & $\begin{array}{r}\text { Number of } \\
\text { MODIS } \\
\text { matchups }\end{array}$ & $\begin{array}{r}\text { Regression } \\
\text { slope } \\
\left(\mathrm{mg} \mathrm{m}^{-3} \text { count }^{-1}\right)\end{array}$ & $\begin{array}{r}\text { Correlation } \\
\text { coefficient }\end{array}$ \\
\hline IMR1 & 0.0072 & 82 & 0.0051 & 0.61 \\
IMR2 & 0.0072 & 69 & 0.0034 & 0.69 \\
IMR3 & 0.0074 & 62 & 0.0049 & 0.63 \\
IMR4 & 0.0073 & 36 & 0.0026 & 0.44 \\
IMR5 & 0.0072 & 42 & 0.0020 & 0.81 \\
IMR6 & 0.0072 & 42 & 0.0013 & 0.63 \\
IMR7 & 0.0073 & 32 & 0.0018 & 0.49 \\
IMR8 & 0.0072 & 46 & 0.0024 & 0.53 \\
\hline
\end{tabular}

ments from an additional float and demonstrated to be quite accurate, as described in the Appendix.

Finally, to test the photoperiod hypothesis we need estimates of the length of daytime. The length of daytime ( $\mathrm{dl}$ in hours) was calculated with the package geosphere from the R software (R Development Core Team, 2016), which computes the length of the daytime for a flat surface for a given latitude and day of year (Forsythe et al., 1995).

\subsection{Float estimates of mixed-layer and euphotic-layer depth}

In the analysis to follow, we need estimates of the mixed layer depth, the layer where density is well homogenized (as a proxy for the layer where mixing is active), and the euphotic layer depth, the depth below which the light level is too low to support photosynthesis.

For all floats but one, the mixed layer depth $(H)$ was computed as the depth at which the density change from its value at $10 \mathrm{~m}$ is $\Delta \sigma_{\theta}=0.01 \mathrm{~kg} \mathrm{~m}^{-3}$ (Kara et al., 2000, 2003). We chose the value of $\Delta \sigma_{\theta}$ that best tracked the region of weak stratification in our data set. This value is consistent with the study of Brainerd and Gregg (1995), who also found that a $\Delta \sigma_{\theta}$ of $0.005-0.01 \mathrm{~kg} \mathrm{~m}^{-3}$ often marks the base of the active turbulent surface layer. The salinity sensor was defective in the float IMR2 and $\mathrm{H}$ was computed as the depth at which the temperature change from its value at $10 \mathrm{~m}$ is $\Delta \theta=0.15^{\circ} \mathrm{C}$, which corresponds to $\Delta \sigma_{\theta} \sim 0.01 \mathrm{~kg} \mathrm{~m}^{-3}$ for a salinity of 35.2 representative of values observed in the Nordic Seas.

The surface value of $[\mathrm{Chl} a]\left([\mathrm{Chl}]_{\mathrm{ML}}, \mathrm{mg} \mathrm{m}^{-3}\right)$ was calculated as the average within the mixed layer (ML). The vertical integral of $[\mathrm{Chl} a]\left(<\mathrm{Chl}>, \mathrm{mg} \mathrm{m}^{-2}\right)$ was obtained by integrating the vertical profile of [Chl $a$ ] from the surface down to the ML base.
We defined the instantaneous euphotic layer depth $\mathrm{i} H_{\mathrm{eu}}(t)$ as the depth below which the light level is too low to support photosynthesis. The threshold light level was set to $1 \mu \mathrm{mol}$ photons $\mathrm{m}^{-2} \mathrm{~s}^{-1}$, corresponding to the lowest light levels at which the temperate diatom Phaeodactylum-tricornutum has been observed to grow (Geider et al., 1986). Following the Beer-Lambert law, the incoming solar radiation was assumed to decay exponentially with depth. The decay rate, equal to the inverse of the diffuse coefficient attenuation of light $K$ $\left(\mathrm{m}^{-1}\right)$, was set to a constant value with depth and throughout the day. Therefore, $K$ was given by

$K=-\frac{\log (0.01)}{H_{1}}$.

The depth $H_{1}$ at which the light intensity is $1 \%$ of its surface value was calculated from $[\mathrm{Chl}]_{\mathrm{ML}}$ using the empirical relationship derived by Morel et al. (2007) from a global data sets of ship-based measurements of $H_{1}$ and surface [Chl $a$ ]:

$$
\begin{aligned}
\log _{10} H_{1}= & 1.524-0.436 \times \log _{10}[\mathrm{Chl}]_{\mathrm{ML}}-0.0145 \\
& \times\left(\log _{10}[\mathrm{Chl}]_{\mathrm{ML}}\right)^{2}+0.0186 \\
& \times\left(\log _{10}[\mathrm{Chl}]_{\mathrm{ML}}\right)^{3} .
\end{aligned}
$$

Whenever $K$ was estimated to be lower than the diffuse coefficient attenuation of light by pure water $K_{\mathrm{w}}=0.027 \mathrm{~m}^{-1}$ (Smith and Baker, 1981), $K$ was set to $K_{\text {w }}$.

$\mathrm{i} H_{\mathrm{eu}}(t)$ was estimated as the depth where the irradiance is $1 \mu \mathrm{mol}$ photons $\mathrm{m}^{-2} \mathrm{~s}^{-1}$ :

$\mathrm{i} H_{\mathrm{eu}}(t)=-\frac{1}{K} \log \left(\frac{1}{\operatorname{iPAR}(0, t)}\right)$.

Finally, we found that $\mathrm{i}_{\mathrm{eu}}(t)$ transitions vary rapidly from zero at night to its maximum value during the day, so that it can be described by a rectangle function which transitions abruptly from zero at night to the value given by Eq. (5). The height of the function is the daily-averaged euphotic layer, $H_{\text {eu }}$, for the whole duration of the day. 


\section{Data analysis}

From autumn to spring, in each of the nine blooms sampled by the floats north of the Arctic Circle ( 2 years each for IMR1, IMR2, IMR3 and 1 year for IMR4, IMR5 and IMR6), we observed the same qualitative pattern in the evolution of the ML depth and the Chl $a$ concentration. Figure 2 shows as an example the potential density anomaly $\left(\sigma_{\theta}\right)$, and [Chl $a$ ], acquired by the float IMR2 from September 2011 to June 2012. (Figures for the other 8 years are displayed in the Supplement Figs. S1-S9.) The ML and euphotic depths are marked as continuous black and white lines respectively. Figure 2a shows that in autumn, from September to December, the $[\mathrm{Chl} a]$ decreased and the ML deepened. The fluorescence signal dropped to its minimum value from late December-early January during the polar night and the values were essentially uniform from the ML down to $1000 \mathrm{~m}$ (not shown) for the following several weeks.

To test whether the polar night ML $[\mathrm{Chl} a]$ was too low to be detected by the fluorometer, we compared the fluorescence measurements collected in the ML, where one expects to find some [Chl $a$ ], with those collected between 900 and $1000 \mathrm{~m}$, where no $[\mathrm{Chl} a]$ is expected and the fluorescence values can be used as an estimate of the dark signal, i.e. fluorescence values measured in the absence of $[\mathrm{Chl} a]$. For each profile collected from December to April, we checked whether the distribution of fluorescence values in the ML was significantly different from the distribution of values between 900 and $1000 \mathrm{~m}$ using a two-sample Mann-WhitneyWilcoxon test. The test confirmed that during winter, the ML fluorescence values were not different from the deep values at the $95 \%$ confidence level (marked with a white asterisk in the figures). In other words, the winter [Chl $a]$ in the ML was on average too low to be detected by the fluorometer. However, the fluorometers detected numerous spikes of higher than average $[\mathrm{Chl} a]$ in the winter ML, but not at depth. This suggests that the winter [Chl $a$ ] was just below detection levels in winter and occasionally the signal emerged above the noise. Similar results were obtained for all other floats deployed north of the Arctic Circle.

The winter [Chl $a$ ] profiles from floats IMR7 and IMR8, which profiled south of Arctic Circle in winter, were very different from those north of the Arctic Circle as shown in Figs. 3 and S11. These profiles were characterized by ML fluorescence values significantly higher than those at deeper depths even in winter, most likely because the [Chl $a$ ] remained high enough to be detected by the fluorometers. This last point is important, because it suggests that a period of complete darkness depletes the phytoplankton biomass so dramatically that most of the time traditional fluorometers cannot detect its concentration.

The ML fluorescence values north of the Arctic Circle emerged from the fluorometer noise level after the end of the polar night. The time of "emergence from noise" $t_{\mathrm{E}}$, was defined as the first instance (second vertical line in

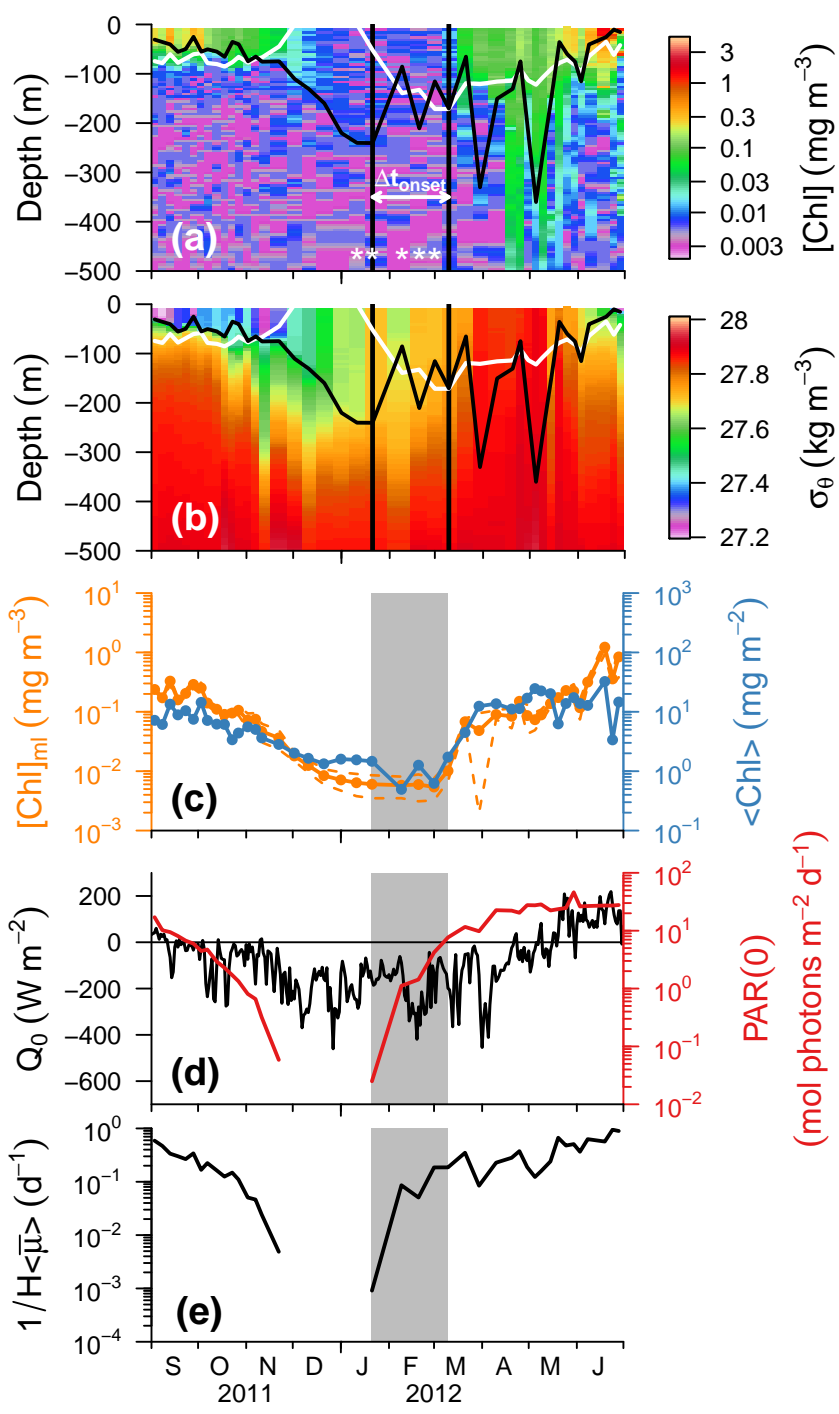

Figure 2. Bloom observed by float IMR2 during the autumnspring 2011-2012. (a) Time evolution of the vertical distribution of [Chl $a$ ]. The asterisks indicate the vertical profiles where the ML fluorescence values are not significantly different from the deep fluorescence values. (b) Time evolution of the vertical distribution of potential density $\sigma_{\theta}$. The black and white continuous lines are the mixed layer, $H$, and euphotic layer depths, $H_{\text {eu }}$, respectively. (c) Time series of the vertical integral and the average concentration of $[\mathrm{Chl} a]$ in the ML $\left(<\mathrm{Chl}>\right.$, blue lines and $[\mathrm{Chl}]_{\mathrm{ML}}$, orange line). The dashed lines are the standard deviations around the average cycle of $[\mathrm{Chl}]_{\mathrm{ML}}$. (d) Time series of the daily surface heat flux $Q_{0}$ (black line) and the daily surface PAR corrected for cloud cover, PAR(0) (red line). (e) Time series of the division rates averaged over the ML depth and over a day as described in Sect. 4.2.1. The two black vertical lines and the gray shading indicate $\Delta t_{\text {onset }}$, the time period during which bloom onset is possible. The first vertical line marks the end of the polar night. The second black vertical line indicates $t_{\mathrm{E}}$, the sampling profile during which the ML fluorescence becomes significantly different from the deep fluorescence values (i.e., emergence of signal from noise). 


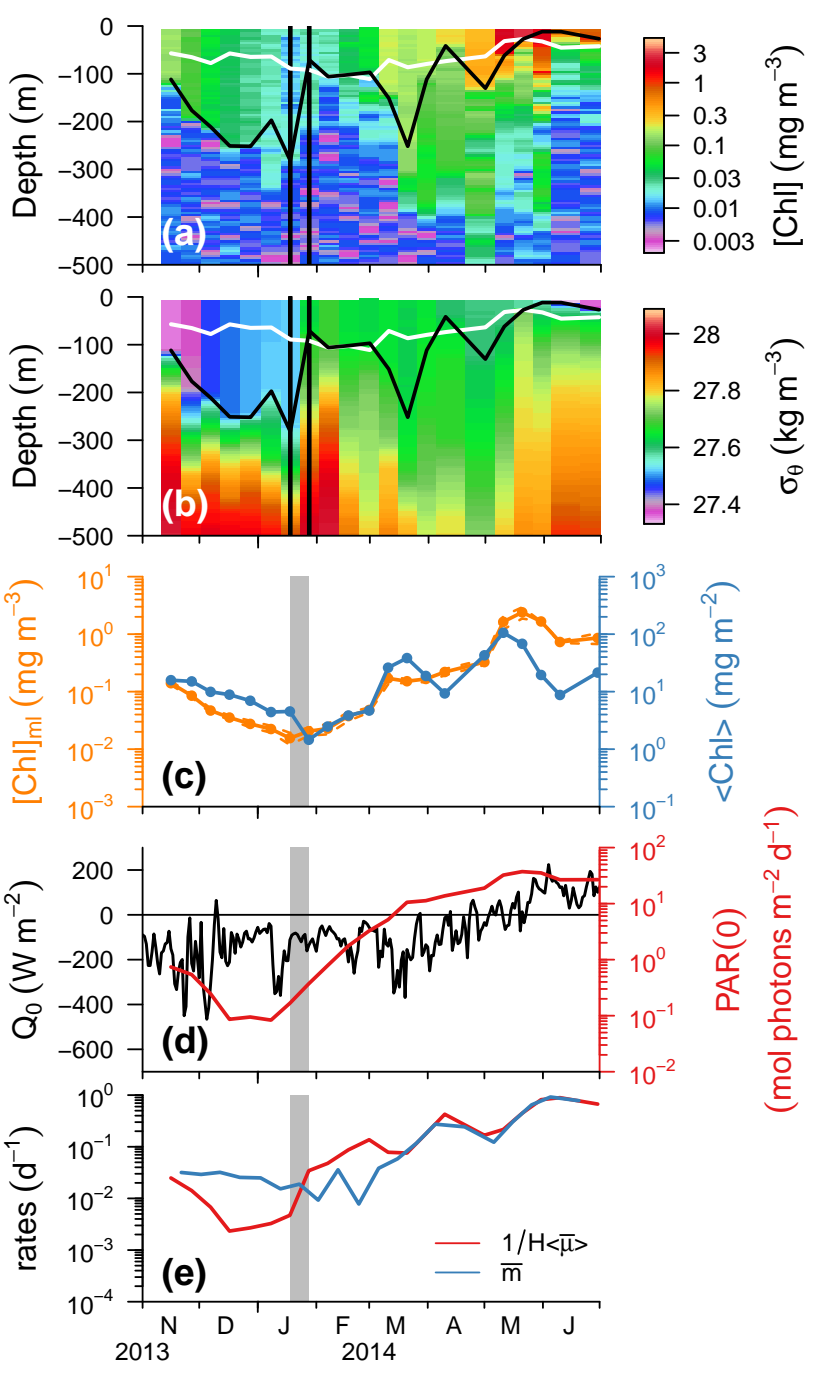

Figure 3. Same as Fig. 2, but for the float IMR7 during the winterspring 2013-2014. The two black vertical lines and the gray shading indicate the onset of the bloom. In panel (e), the continuous red and blue lines are the daily mixed layer averaged division rate $(1 / H<\bar{\mu}>)$ and the phytoplankton loss rates $(m)$, respectively, computed as discussed in Sect. 4.2.

Fig. 2), when the ML fluorescence values became significantly greater than the deep fluorescence values as per the Mann-Whitney-Wilcoxon test in three consecutive profiles ( $\sim 1$ month). The positions of the floats at $t_{\mathrm{E}}$ for all floats deployed north of the Arctic Circle are shown as black dots in Fig. 1.

The net accumulation of [Chl $a$ ] starting at $t_{\mathrm{E}}$ was detected both in surface $[\mathrm{Chl}]_{\mathrm{ML}}$ and vertically integrated $\langle\mathrm{Chl}\rangle$, and lasted until June-July. We cannot determine whether accumulation started at $t_{\mathrm{E}}$ or earlier, when the fluorescence values were too low to be detected by the fluorometer. Given that photoautotrophic growth is not possible without light, we conclude that the bloom started sometime between the end of the polar night and $t_{\mathrm{E}}$. We will refer to this time inter-
Table 3. Time of "emergence from noise" $\left(t_{\mathrm{E}}\right)$ in year-day, and latitude $\left({ }^{\circ} \mathrm{N}\right)$ at $t_{\mathrm{E}}$. The events have been sorted in increasing day of the year from top to bottom.

\begin{tabular}{lrr}
\hline Bloom & $t_{\mathrm{E}}$ & Latitude \\
\hline IMR1 2011-2012 & 59 & 66.7 \\
IMR1 2010-2011 & 62 & 68.5 \\
IMR5 2014-2015 & 66 & 72.5 \\
IMR3 2011-2012 & 69 & 69.9 \\
IMR4 2014-2015 & 69 & 70.4 \\
IMR2 2011-2012 & 70 & 70.5 \\
IMR6 2014-2015 & 72 & 69.9 \\
IMR3 2010-2011 & 95 & 69.4 \\
IMR2 2010-2011 & 96 & 69.0 \\
\hline
\end{tabular}

val as $\Delta t_{\text {onset }}$ (shown as two black vertical lines and a gray shading area in Fig. 2).

Figure 4 shows the surface heat fluxes, the ML depth, the daily averaged PAR and the length of daytime, with time shifted so that the origin is at $t=t_{\mathrm{E}}$ for each of the nine float years. The time of "emergence from noise" for seven out of nine events (blue lines) occurred when the day length was between 9 and $11 \mathrm{~h}$ (Fig. 4d) and PAR(0) was between 3 and $8 \mathrm{~mol}$ photons $\mathrm{m}^{-2} \mathrm{~d}^{-1}$ (Fig. 4c). The surface heat flux $Q_{0}$ was moderately negative, between 100 and $200 \mathrm{~W} \mathrm{~m}^{-2}$ (Fig. 4a), and the ML was as likely to be shoaling as deepening (Fig. 4b). Table 3 shows that $t_{\mathrm{E}}$ occurred between yearday 59 and 72 for all years. Moreover, most of the time, $t_{\mathrm{E}}$ occurred earlier for the floats that were further south. For the two other events (orange lines), Fig. 4a and b show that the time of "emergence from noise" coincided with the shutdown of convection and the sudden shoaling of the ML, when the day length was approximately $14 \mathrm{~h}, \operatorname{PAR}(0)$ was $\sim 12 \mathrm{~mol}$ photons $\mathrm{m}^{-2} \mathrm{~d}^{-1}$ and the year-day was between 95 and 96 (Table 2).

Two possible bloom onset scenarios emerge from this simple preliminary analysis of the float data. One interpretation is that blooms started at $t=t_{\mathrm{E}}$, when the accumulation of phytoplankton biomass was first detected by the fluorometer, and the photoperiod (the duration of a phytoplankton cell daily exposure to light) reached a critical value of $10 \pm 1 \mathrm{~h}$. For the seven events with shallow MLs, the photoperiod was equal to the day length (see Fig. 5). In the two cases with deep MLs, the phytoplankton did not experience $10 \pm 1 \mathrm{~h}$ of light until the mixing subsided and allowed cells to linger at the surface - this is shown more quantitatively in the next section. This interpretation is supported by two lines of evidence. First, it is statistically unlikely that the co-occurrence of a particular day length and the first increase in chlorophyll detected by all fluorometers is mere coincidence, as it would have to be argued if $t_{\mathrm{E}}$ represented the emergence of fluorescence signal from background noise. Second, the repeated detection of significant fluorescent spikes in the winter ML profiles suggests that the 
(a)

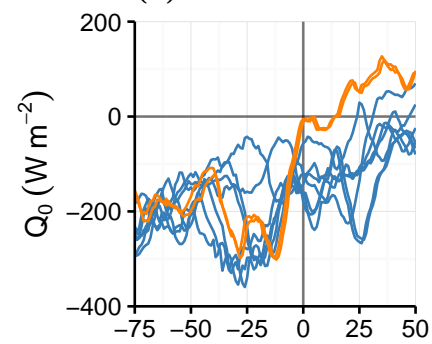

(c)

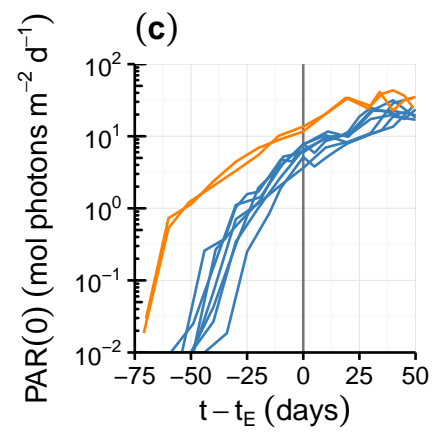

(b)

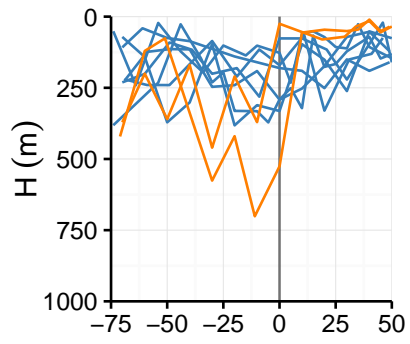

(d)

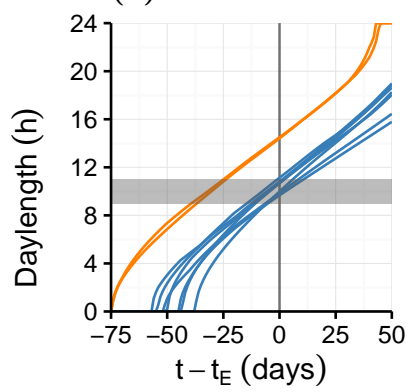

Figure 4. (a) Time series of surface heat flux $\left(Q_{0}\right)$, (b) mixed layer depth $(H)$, (c) the daily surface PAR corrected for cloud cover $[\operatorname{PAR}(0)]$, and (d) day length relative to the time of "emergence from signal to noise" $t_{\mathrm{E}}$ for the nine bloom events observed by the floats. The gray shading indicates the critical day length range, namely $9-11 \mathrm{~h}$ The blue lines represent the cases where the first accumulation of biomass was detected when the sea surface heat fluxes were still negative. The orange lines represent the cases where the first accumulation of biomass was detected when the wintertime cooling shut down. A 10-day moving average has been applied to $Q_{0}$.

winter $[\mathrm{Chl}]_{\mathrm{ML}}$ was just below detection levels and thus the emergence from noise was likely close to the actual increase in chlorophyll. (We focus our discussion on photoperiod, because attempts to correlate the bloom onset with daily averaged light or maximum iPAR did not collapse the data as well due to large cloud coverage variations from year to year.)

A second interpretation is that all bloom onsets are consistent with the critical depth hypothesis. Blooms started when phytoplankton division rates became larger than the phytoplankton loss rates. However, the biomass accumulation was so weak during $\Delta t_{\text {onset }}$ that went undetected by the fluorometers. In this interpretation, the coincidence of the emergence of the fluorescence signal from noise and the photoperiod must be considered a statistical fluke. We develop the theoretical framework to test these two possible scenarios in the next section.

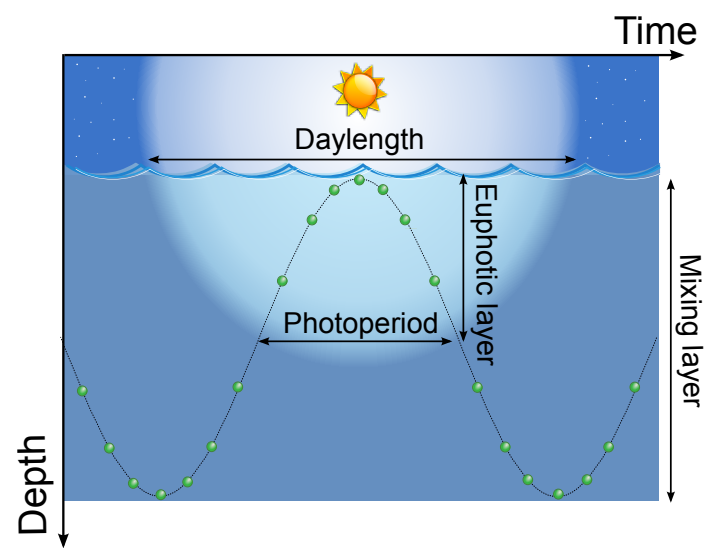

Figure 5. Schematic of the trajectory of phytoplankton cells in the mixing layer. The photoperiod is the time spent by the cell in the euphotic layer. In the open ocean, this time depends on the day length, the depth of the euphotic layer, the strength and the vertical extent of the turbulence mixing the cells.

\section{Theory}

\subsection{Critical photoperiod hypothesis}

In the Nordic Seas, the insolation drops dramatically in winter. As one moves north of the Arctic Circle, there are progressively longer periods of complete winter darkness, the polar nights. Phytoplankton growth is simply impossible for days to weeks, depending on the latitude. Under these conditions, the focus must shift on understanding how phytoplankton cells survive the winter darkness to give rise to a bloom in spring. With no energy to photosynthesize, cells will likely strive to reduce losses due to metabolic respiration, grazing pressure, parasitism, and viral infections. We review recent literature suggesting that the cells enter into a dormant state during polar nights and then wake up, when the day length crosses some threshold.

Eilertsen (1995) studied the onset of spring blooms in the coastal waters of the Nordic Seas. While coastal blooms may be different from open ocean blooms - the focus of our study - some key findings are worth reviewing. These blooms are dominated by marine diatoms in the early stages and begin approximately the same calendar day every year, despite highly variable year-to-year environmental conditions. Field studies showed that in the coastal waters of Northern Norway, the marine diatoms turn into resting spores during winter to drastically reduce respiration and survive several weeks of darkness (Degerlund and Eilertsen, 2010). The heavy spores sink to the bottom a few hundred metres below the surface into permanent darkness. However, they are occasionally re-suspended towards the surface by sudden mixing events triggered by atmospheric storms. Eilertsen et al. (1995) speculated that the spores germinate when the day length exceeds a critical threshold; estimated between 7 and $12 \mathrm{~h}$ (Eilertsen and Wyatt, 2000). Note that this survival strat- 
egy is not specific to diatoms. Many species of dinoflagellates and chrysophytes produce cysts at the end of summer or in response to environmental stimuli, such as nutrient limitation, and remain dormant until the following spring. Some are known to germinate in response to light or nutrient stimulation. Others germinate after a specific period of time or in response to photoperiod (McMinn and Martin, 2013).

A day length control has never been documented in the open ocean of the Nordic Seas, possibly due to the dearth of ocean colour measurements in winter when cloud coverage is pervasive. Moreover, in the open ocean the hypothesis must be modified because the photoperiod can be shorter than the day length, when strong mixing keeps cells below the euphotic layer for some part of the daytime as shown in Fig. 5.

It has been documented that plant systems determine the photoperiod by sensing the duration of darkness (Hamner, 1940; Hamner and Bonner, 1938). In an ocean environment photoperiod based on "darkness-length" is not a viable strategy: the length of darkness correlates primarily with the strength of mixing, which keeps cells away from the surface, and not with the number of light hours at the surface. If cells relied on sampling the number of dark hours, they would germinate every time a strong storm passed by, suddenly deepening the ML and increasing the number of hours without light they experienced. Therefore, photoperiod in the ocean must be based on the length of "light-hours", if it is to be a viable strategy. We are not aware of studies that investigated how phytoplankton detect photoperiod, but our results suggest that it would be an interesting area of research.

The critical photoperiod hypothesis requires that individual cells can detect the duration of light. Thus, we compute the sustained light exposure of individual cells, not of the entire population. In the Appendix, we derive an approximate formula to calculate the photoperiod in the open ocean as a function of day length, euphotic layer depth and strength of mixing. We first show that cells spend a time $T_{\mathrm{eu}}$ in the euphotic layer depth,

$$
T_{\mathrm{eu}}=\frac{H \operatorname{arcos}\left(1-2 H_{\mathrm{eu}} / H\right)}{\sqrt{2} A\left|B_{0} H\right|^{1 / 3}},
$$

where $H_{\mathrm{eu}}$ is the euphotic layer depth, $H$ is the ML depth, $B_{0}$ is the surface buoyancy flux and $A$ a constant coefficient equals to 0.45 . If the residency time $T_{\mathrm{eu}}$ is longer than the day length or the ML depth is shallower than the euphotic depth, then the photoperiod experienced by phytoplankton cells in the ocean is equal to the day length; otherwise the photoperiod is equal to $T_{\mathrm{eu}}$, and shorter than the day length.

In Sect. 5, we will confirm that the first accumulation of chlorophyll detected by all fluorometers occurred at the same critical photoperiod, supporting the hypothesis that the onset of the Nordic Seas blooms is consistent with a critical photoperiod hypothesis.

\subsection{Critical depth hypothesis}

Following Sverdrup (1953), the changes in phytoplankton concentration $P(z, t)$ is a response to changes in light, mortality and vertical mixing can be described by a partial differential equation:

$$
\begin{aligned}
\frac{\partial P(z, t)}{\partial t}= & \mu(z, t) P(z, t)-m(z, t) P(z, t) \\
& +\frac{\partial}{\partial z}\left(\kappa_{\mathrm{T}}(z, t) \frac{\partial P(z, t)}{\partial z}\right),
\end{aligned}
$$

where $z$ is the vertical coordinate, $t$ is time, $\mu$ is the cell division rate, $m$ is the phytoplankton loss rate and $\kappa_{\mathrm{T}}$ is the vertical eddy diffusivity, which represents the rate at which turbulence mixes phytoplankton in the vertical. The effect of light on growth is captured by the depth and time dependence of the division rate. Nutrient limitation on growth is ignored, because in the early phase of blooms in the Nordic Seas nutrients are plentiful. Finally, we ignore the effect of lateral advection of phytoplankton by oceanic currents. This is a reasonable assumption as long as the currents are weak or the phytoplankton concentrations are uniform in the horizontal. We cannot test whether this is always the case for the float data, so we will use this equation as a working hypothesis and check to what extent the terms included in the right-hand side are sufficient to explain the observed changes in $P(z, t)$.

When turbulence is strong, like in the Nordic Seas winter, the phytoplankton is mixed so fast that it remains uniform within the ML and we can ignore the $z$ dependence in $P$. We also assume that there is no phytoplankton flux through the surface and the ML base. Integrating Eq. (7) over the ML in addition to averaging over a full day (indicated by an overbar), we obtain an expression for the phytoplankton growth rate:

$\int_{-H}^{0} \frac{\partial \bar{P}}{\partial t} \mathrm{~d} z=\langle\bar{\mu}\rangle \bar{P}-\langle\bar{m}\rangle \bar{P}$,

where $<>$ represents the vertical integral between the surface and the ML base at $z=-H$. The total population size can grow when the left-hand side is positive, or

$\langle\bar{\mu}\rangle \geq\langle\bar{m}\rangle$.

If following Sverdrup (1953), we assume that the losses are independent of depth, since they depend on phytoplankton and zooplankton concentrations which are uniform with depth, then $\langle\bar{m}\rangle=H \bar{m}$, and accumulation occurs if the ML depth is shallower than a critical depth

$H \leq H_{\mathrm{c}}=\frac{\langle\bar{\mu}\rangle}{\bar{m}}$

or stated differently; when the daily mixed layer averaged division rate is greater than the loss rates:

$\frac{1}{H}\langle\bar{\mu}\rangle \geq \bar{m}$. 
Despite its simplicity, the condition necessary for bloom onset in the limit of strong turbulence is difficult to test quantitatively with profiling float data. Testing Eq. (11) requires in situ observations of phytoplankton division and loss rates, which presently cannot be measured with autonomous platforms. Phytoplankton division rate can however be estimated using bio-optical models. Then, phytoplankton loss rates can then be derived from Eq. (8) by subtracting the net accumulation rate (i.e., $\frac{1}{\bar{P}} \int_{-H}^{0} \frac{\partial \bar{P}}{\partial t} \mathrm{~d} z$ ) from estimates of $\langle\bar{\mu}\rangle$.

To avoid any confusion down the road, it is worth emphasizing that the critical depth framework remains the key approach to study the development of blooms. There is however, an ongoing discussion as to what are the key variables that change at bloom onset and prompt Eq. (11) to be first satisfied. Sverdrup (1953) hypothesized that Eq. (11) is typically satisfied at the end of winter, when the ML depth $H$ shoals results in an increase of $\frac{1}{H}\langle\bar{\mu}\rangle$. Behrenfeld et al. (2013, 2014) argued that the left- and right-hand side terms are always very close to exact balance. Blooms start whenever a small perturbation in the system drives $\frac{1}{H}\langle\bar{\mu}\rangle$ to increase above $\bar{m}$, including late autumn conditions when $\bar{m}$ decreases rapidly due to ML deepening and associated dilution of grazers (Behrenfeld, 2010). Finally, it is also possible for blooms to start in response to an increase in light, and hence $\langle\bar{\mu}\rangle$, with no changes in the other variables. In the following, we will use the critical depth framework to interpret the float data, with the goal of determining what processes first trigger the bloom.

\subsubsection{Phytoplankton division rates}

The division rate $\mu$ in Eq. (7) represents the division rate of the overall phytoplankton population. We used the physiological model of Geider et al. (1997), together with the photophysiological parameters from Antoine and Morel (1996), to get an estimate of $\mu(z, t)$.

Geider et al. (1997) proposed that the nutrient-saturated division rates are well described by the equation:

$\mu(z, t)=\mu_{\max }\left(1-e^{-\frac{\alpha_{\mathrm{Chl}} \times \theta c \times \operatorname{PAR}(z, t)}{\mu_{\max }}}\right)$,

where $\mu_{\max }$ is the maximum value of the division rate under light-saturated conditions $\left(\mathrm{s}^{-1}\right), \alpha_{\mathrm{Chl}}$ is the $\mathrm{Chl} a$ specific initial slope of the photosynthesis-irradiance curve [gC gChl $a^{-1}$ ( $\mu \mathrm{mol}$ photons) $)^{-1} \mathrm{~m}^{2}$ ], and $\theta_{\mathrm{c}}$ is the chlorophyll to carbon ratio. The maximum value of the division rate under light-saturated conditions is represented as a function of temperature following Bissinger et al. (2008):

$\mu_{\max }=\mu_{\mathrm{ref}} e^{0.0631 \mathrm{MLT}}$,

where $\mu_{\text {ref }}=9.4 \times 10^{-6} \mathrm{~s}^{-1}$, and MLT is the average temperature in the ML. The Chl $a$-specific initial slope of the photosynthesis-irradiance curve is set to $6.4 \times 10^{-6} \mathrm{gC}$ $\mathrm{gChl} a^{-1}$ ( $\mu$ mol photons $)^{-1} \mathrm{~m}^{2}$, a value used in a global light-photosynthesis model of oceanic primary production (Antoine and Morel, 1996). The chlorophyll to carbon ratio $\theta_{\mathrm{c}}$ is set to $0.04 \mathrm{gChl} a \mathrm{gC}^{-1}$, a value representative of photoacclimation to extremely low light levels in the subpolar North Atlantic (Xing et al., 2014).

The vertical profile of iPAR ( $\mu \mathrm{mol}$ photons $\mathrm{m}^{-2} \mathrm{~s}^{-1}$ ) is modelled through:

$\operatorname{iPAR}(z, t)=\operatorname{iPAR}(0, t) e^{K z}$.

Finally, we are interested in sustained growth rates for at least a day, not transient growth rates lasting only a few hours. Consistently we averaged Eq. (12) over a full day in addition to integrating over the full ML depth:

$$
\langle\bar{\mu}\rangle=\frac{1}{1 \text { day }} \int_{0}^{1 \text { day }} \int_{-H}^{0} \mu_{\max }\left(1-e^{-\frac{\alpha \operatorname{Chl} \times \theta c \times \operatorname{PAR}(z, t)}{\mu_{\max }}}\right) \mathrm{d} z \mathrm{~d} t .
$$

\subsubsection{Phytoplankton loss rates}

Phytoplankton loss rates are given by the sum of grazing, viral lysis and parasitism. These terms are very difficult to estimate in situ. Instead we will estimate the loss rates as the residual between the division rates, $\langle\bar{\mu}\rangle$, and the phytoplankton accumulation rates averaged over a day.

Assuming that phytoplankton concentration and loss rates are uniform over the ML depth, we can derive two separate equations to estimate loss rates during time of ML deepening and shoaling respectively (Behrenfeld et al., 2013). When the ML deepens and entrains fluid with no phytoplankton from below, Eq. (7) can be vertically integrated and time averaged over a few days to obtain an equation for the standing stock, $\langle\bar{P}\rangle=\int_{-H}^{0} \bar{P}(z) \mathrm{d} z=H \bar{P}$,

$\frac{\mathrm{d}\langle\bar{P}\rangle}{\mathrm{d} t}=\frac{1}{H}\langle\bar{\mu}\rangle\langle\bar{P}\rangle-\bar{m}\langle\bar{P}\rangle$,

where we ignored temporal correlations between the daily variations in division rates and the slower variations in phytoplankton concentrations and loss rates. Equation (16a) can be used to estimate the vertically integrated and time-averaged loss rates, as,

$\bar{m}=\frac{1}{H}\langle\bar{\mu}\rangle-\frac{1}{\langle\bar{P}\rangle} \frac{\mathrm{d}\langle\bar{P}\rangle}{\mathrm{d} t}$.

When the ML shoals and leaves phytoplankton behind, the time and vertical average of Eq. (7) gives

$\frac{\mathrm{d} \bar{P}}{\mathrm{~d} t}=\frac{1}{H}\langle\bar{\mu}\rangle \bar{P}-\bar{m} \bar{P}$,

where we assumed that $\bar{P}$ and $\bar{m}$ are constant in the ML,

$\bar{m}=\frac{1}{H}\langle\bar{\mu}\rangle-\frac{1}{\bar{P}} \frac{\mathrm{d} \bar{P}}{\mathrm{~d} t}$. 
Equations (16b) and (17b) are very similar except for the appearance of a standing stock $\langle\bar{P}\rangle$ versus a concentration $\bar{P}$ in the right-hand side. In Sect. 5 we will estimate the phytoplankton loss rates from Eqs. (16b) or (17b), depending on whether the ML is deepening or shoaling, estimates of $\langle\bar{\mu}\rangle$ based on the algorithm given in Sect. 4.2.1 and rates of population accumulation from [Chl $a]$ float data.

\section{Testing bloom onset hypotheses}

Using the theoretical framework that we developed in the last section, we now test the two bloom onset scenarios that emerged from the preliminary analysis of the float data.

\subsection{Critical photoperiod hypothesis}

First we test whether the start of the Nordic Seas blooms is consistent with the critical photoperiod hypothesis. To do so, we estimate the photoperiod at the time when the fluorometers detected the first accumulation of biomass, i.e. at $t=t_{\mathrm{E}}$. The photoperiod is calculated with the algorithm presented in the Appendix. Notice that in this section we therefore assume that the bloom onset coincided with the first increase detected in fluorescence.

In Sect. 3, we anticipated that, at $t=t_{\mathrm{E}}$, the day length was between 9 and $11 \mathrm{~h}$ for the 7 years when biomass accumulation was detected with negative sea surface heat fluxes. The formula we developed in the Appendix suggests that for these seven blooms the day length is a pretty accurate estimate of the photoperiod, because the cells remained in the euphotic layer for the whole day length when the surface heat losses are smaller than $200 \mathrm{~W} \mathrm{~m}^{-2}$. The onset of these blooms is therefore consistent with a critical photoperiod of $10 \pm 1 \mathrm{~h}$. The day length increases by $1 \mathrm{~h}$ every 10 days along the Arctic circle, so the photoperiod cannot be determined to better than $1 \mathrm{~h}$ with the 10-day float sampling frequency.

In the remaining two blooms with winter mixed layers much deeper than $200 \mathrm{~m}$, the fluorometers detected the first biomass accumulation when the surface heat losses subsided at the end of winter. For these two blooms, in the weeks preceding $t=t_{\mathrm{E}}$, when the day length was between 9 and $14 \mathrm{~h}$, the heat loss was constantly above $200 \mathrm{~W} \mathrm{~m}^{-2}$ (Fig. 4a). In the Appendix, we show that the strong heat loss generated such intense mixing that the cells never experienced more than $8 \mathrm{~h}$ of light. Hence, the photoperiod experienced by the cells did not reach the $10 \mathrm{~h}$ critical threshold until the cooling finally subsided at the end of March. This suggests that the onset of these two late blooms is also consistent with a critical photoperiod of $10 \pm 1 \mathrm{~h}$.

\subsection{Critical depth hypothesis}

Next, we test whether the start of the Nordic Seas blooms is consistent with the critical depth hypothesis, i.e. the blooms begin when $\frac{1}{H}\langle\bar{\mu}\rangle \geq \bar{m}$ before they are detected by the fluo- rometers. In this interpretation, the coincidence of the emergence of the fluorescence signal from noise and the photoperiod must be considered a statistical fluke. Since we cannot determine the loss rates during part of the winter north of the Arctic Circle, we first conduct the analysis on the two events that did not experiment the polar night. Then, assuming that the winter grazing pressure north of the Arctic Circle is no larger than south of it (phytoplankton concentrations are smaller and ML deeper), we investigate whether the Nordic Seas blooms started according to the critical depth hypothesis.

For the two blooms sampled south of the Arctic Circle, $\langle\bar{\mu}\rangle$ is estimated as explained in Sect. 4.2.1. The phytoplankton loss rates are computed as a residual between division and accumulation rates as described in Sect. 4.2.2. The last two panels of Fig. 3 show the time series of the daily averaged insulation, of $\frac{1}{H}\langle\bar{\mu}\rangle$ and of $\bar{m}$ for the float IMR7 from November 2014 to June 2015 (an equivalent figure for the float IMR8 is displayed in Fig. S11). The figure reveals that $\frac{1}{H}\langle\bar{\mu}\rangle$ primarily tracks the increase in insolation; both increase monotonically by close to 2 orders of magnitude from January to April. In autumn and spring, the division and loss rates instead track each other very closely. In winter, the loss rates never drop below $0.02-0.05 \mathrm{~d}^{-1}$, hereinafter denoted as $\bar{m}_{\text {winter, }}$, whereas $\frac{1}{H}\langle\bar{\mu}\rangle$ drops to extremely low values of about $2 \times 10^{-3} \mathrm{~d}^{-1}$. A loss rate within a range of $0.05-0.1 \mathrm{~d}^{-1}$ is believed to describe background non-grazing phytoplankton mortality rates (Behrenfeld et al., 2013; Dutkiewicz et al., 2015; Evans and Parslow, 1985; Moore et al., 2002). This result supports the hypothesis that grazing was very weak in winter.

The bloom onset did not seem to track changes in ML depth. The onset was estimated as the time when $[\mathrm{Chl}]_{\mathrm{ML}}$ or $<$ Chl $>$ first increased. For the float-year IMR7 2014-2015, the bloom onset occurred during a rapid shoaling of the ML, resulting in an increase of $[\mathrm{Chl}]_{\mathrm{ML}}$ and a decrease in $<\mathrm{Chl}>$. For the float-year IMR8 2013-2014, the bloom onset coincided with a rapid deepening of the ML, resulting in an increase of $\left\langle\mathrm{Chl}>\right.$ and a decrease in $[\mathrm{Chl}]_{\mathrm{ML}}$ due to dilution with fluid with no phytoplankton from below. Figures $3 \mathrm{e}$ and S11e show that $\frac{1}{H}\langle\bar{\mu}\rangle$ changed somewhat in response to these ML changes, but much less than the response to the rapid increase in isolation. We conclude that the blooms south of the Arctic Circle could have started because of the increase in insolation, which allowed division rates to exceed losses. This scenario would be consistent with the critical depth hypothesis, but not with Sverdrup's assumption that it is changes in the ML depth that are key.

The same analysis is repeated for the nine blooms sampled north of the Arctic Circle. The analysis can start only after $t_{\mathrm{E}}$, because prior to that time [Chl $\left.a\right]$ measurements are dominated by noise and we cannot estimate loss rates. The average loss rates at $t_{\mathrm{E}}$ for all nine blooms were $0.05 \pm 0.04 \mathrm{~d}^{-1}$. This value is consistent with the winter phytoplankton loss 
rates range estimated south of the Arctic Circle. It is therefore safe to assume that loss rates in winter were no larger than $\sim 0.05 \mathrm{~d}^{-1}$. In order to test if the Nordic Seas bloom onsets are consistent with the critical depth hypothesis, we next test whether $\frac{1}{H}\langle\bar{\mu}\rangle$ exceeded the upper bound for $\bar{m}_{\text {winter }}$ of $0.05 \mathrm{~d}^{-1}$ during the time between the end of polar night and $t_{\mathrm{E}}$.

Figure 6a shows the time series of $\frac{1}{H}\langle\bar{\mu}\rangle$ with time axis shifted so that for each of the 9 years the origin is at $t_{\mathrm{E}}$. In all years, $\frac{1}{H}\langle\bar{\mu}\rangle$ exceeded $0.05 \mathrm{~d}^{-1}$ within the month prior to $t=t_{\mathrm{E}}$. Moreover, as shown for the events sampled south of the Arctic Circle, $\frac{1}{H}\langle\bar{\mu}\rangle$ primarily tracked the increase in insolation. Figure $6 \mathrm{~b}$ shows that the dramatic increase in $\frac{1}{H}\langle\bar{\mu}\rangle$ disappears, if the seasonal increase in surface insolation is ignored $-\operatorname{iPAR}(0, t)$ was replaced with a periodic repetition of the daily cycle of incoming surface insolation on 1 March at $70^{\circ}$. Surprisingly, even the deep MLs sampled by floats IMR2 and IMR3 had little impact in delaying the increase in division rates driven by the surface insolation. It is however possible that the delay in $t_{\mathrm{E}}$ for these two events is an artifact of [Chl $a$ ] remaining too low to be detected in the deep MLs.

Our data are thus consistent with the hypothesis that the Nordic Seas blooms started according to the critical depth hypothesis. But the analysis falls short of proving that the deepening of critical depth at the end of winter is the trigger of the bloom. Such a proof would require accurate estimates of winter division and loss rates, which are simply impossible to obtain with present technology. Moreover, fluorometers with lower noise threshold are needed to document the first accumulation of chlorophyll in the Nordic Seas winter, when concentrations are extremely low.

In conclusion, the bloom onset is consistent with the photoperiod hypothesis if the chlorophyll started to accumulate when it was first detected by the fluorometer. However, it is also possible that the bloom started earlier according to the critical depth hypothesis, if some weak accumulation began earlier in the season at levels too low to be detected by fluorometers. Our opinion is that the photoperiod hypothesis is more likely to be correct, because it is hard to believe that the co-occurrence of a critical photoperiod of $10 \pm 1 \mathrm{~h}$ and the increase in chlorophyll detected by the fluorometers is mere coincidence.

\section{Conclusions}

In the Nordic Seas, north of the Arctic Circle, insolation drops so dramatically in winter that phytoplankton growth is impossible for days to weeks during polar nights. The goal of this paper was to investigate how phytoplankton populations survive such harsh winter conditions and what triggers their resurgence in spring. Satellite data are hardly ever available at these latitudes due to continuous cloud coverage. Instead, we used in situ data of [Chl $a$ ] and CTD from six bio-optical floats deployed in this region. (a)

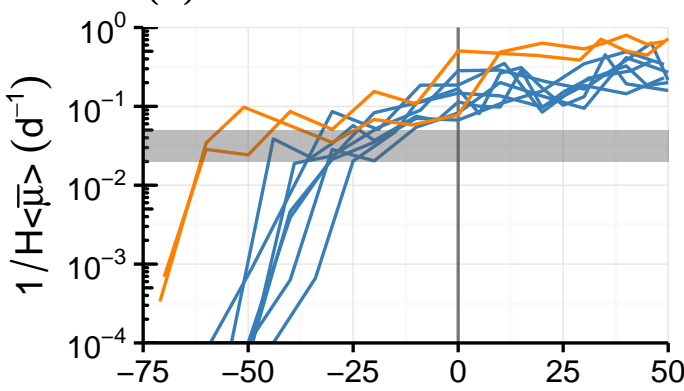

(b) $\operatorname{iPAR}(0, t)=c s t$

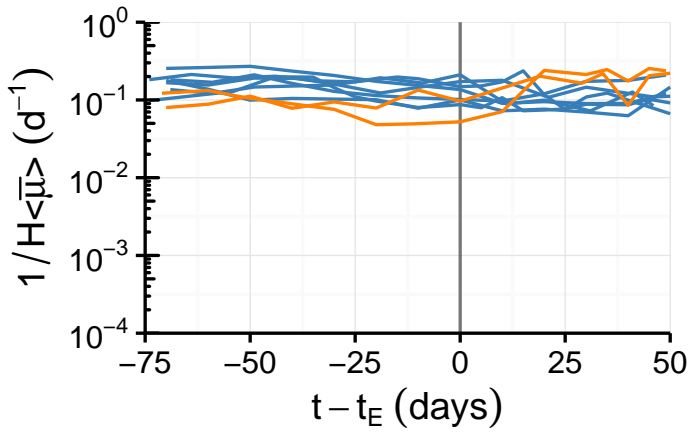

Figure 6. Time series of the daily mixed layer-averaged phytoplankton division rate $\left(\frac{1}{H}\langle\bar{\mu}\rangle\right)$ based on Eq. (15) for the nine events observed by the floats. All time series are shifted relative to $t_{\mathrm{E}}$ The blue lines represent the cases where the first accumulation of biomass was detected when the sea surface heat fluxes were still negative. The orange lines represent the cases where the first accumulation of biomass was detected when the wintertime cooling shut down. The horizontal gray shading represents the winter phytoplankton loss rates range, namely $0.02-0.05 \mathrm{~d}^{-1}$. (a) Estimates based on a clear sky model of incoming irradiance for the days and latitudes sampled by each float (Gregg and Carder, 1990). (b) Estimates based on the periodic repetition of the daily cycle of incoming surface insolation on 1 March at $70^{\circ} \mathrm{N}$.

Not surprisingly, the Chl a concentrations dropped dramatically in winter, during polar nights, to values lower than reported by floats south of the Arctic Circle. The values were so low that they were below or at the noise threshold levels of the traditional fluorometers mounted on the floats. After a few months, at the end of winter, the Chl $a$ concentrations started increasing very rapidly. We cannot definitively conclude that this increase marked the bloom onset, because low [Chl $a$ ] accumulation could have started earlier in the season at levels below the fluorometers detection levels. This uncertainty in the exact timing of the bloom onset implies that the float data are consistent with two possible scenarios for the onset of blooms in the Nordic Seas: the critical photoperiod hypothesis and the critical depth hypothesis.

In all years sampled by the floats, the increase in Chl $a$ concentrations was detected when the phytoplankton experienced a photoperiod of $10 \pm 1 \mathrm{~h}$, i.e. when phytoplankton 
cells experienced approximately 10 light hours in a day for the first time in the season. The critical photoperiod was equal to a $10 \mathrm{~h}$ day length, when mixing was weak, but it corresponded to a longer day length, when mixing was strong and kept cells away from the well-lit surface. We speculate that similar to what has been documented in the coastal waters of the Nordic Seas, phytoplankton enters in resting stages during polar night in order to minimize energy expenditure. Unlike in coastal waters, the resting stage cannot be in the form of spores or cysts that are too dense to float in the open ocean. Rather the resting stage must be in the form of vegetative cells whose density is closer to that of the water and can remain re-suspended for long periods of time (D'Asaro, 2008). A bloom develops when the cells experience a photoperiod of $10 \pm 1 \mathrm{~h}$ and emerge from the resting stages.

The chlorophyll concentrations dropped below the noise level of our fluorometers in winter. It is thus possible that some weak biomass accumulation started early in the season, but at concentrations too weak to be detected by the fluorometers. We thus tested whether conditions were favourable for bloom initiation prior to the first $[\mathrm{Chl} a]$ increase measured by the fluorometers. In particular, we investigated whether phytoplankton division rates were likely to have exceeded losses in the weeks between the end of the polar night and the first $[\mathrm{Chl} a]$ increase, consistent with the more commonly accepted critical depth hypothesis. The float data suggest that changes in the ML depth and heat losses had little impact on the division rates in the Nordic Seas at the end of winter. Furthermore, the winter grazing rates were likely lower than non-grazing mortality due to parasitism and viral lysis. Thus dilution of grazers did not appear to have much of an effect on the increase in phytoplankton populations. Insolation, instead, increased very rapidly at the end of winter north of the Arctic Circle and may have driven an increase in division rates large enough to overcome losses. According to our analysis the increased insolation ought to have triggered the blooms before they were detected by the fluorometers. A possible scenario, given that the fluorometer signals were dominated by noise in winter. This is a scenario we cannot, however, test with our data.
We tend to favour the photoperiod scenario, because it is hard to believe that the co-occurrence of the bloom onset with a specific photoperiod is pure coincidence. However, the photoperiod hypothesis implies that all species within the population start dividing at a critical photoperiod. To our knowledge, such behaviour has never been explored. Therefore, future work will have to investigate which species within the population display a critical photoperiod behaviour.

Theory and models of high-latitude ocean blooms do not consider the possibility that phytoplankton enter and exit from resting stages in response to changes in photoperiod. This omission can potentially impact the whole representation of these ecosystems, because the timing of bloom initiation has been shown to have an impact on all the trophic levels affecting, for example, the survival of larval fish (Platt et al., 2003) and the hatching time of shrimp eggs (Koeller et al., 2009). Furthermore, an accurate representation of the timing and evolution of the bloom is crucial to represent the ocean ecosystem response to climate change and its impact on the ocean carbon budget.

\section{Data availability}

These data were collected and made freely available by the International Argo Program and the national programs that contribute to it (http://www.argo.ucsd.edu, http://argo. jcommops.org). The Argo Program is part of the Global Ocean Observing System. 


\section{Appendix A: Irradiance model performance evaluation}

We used measurements of photosynthetically active radiation (PAR) made by an additional float IMR9 to evaluate our PAR estimates (as described in Sect. 2.4). The float was deployed in the Nordic Seas by the Institute of Marine Research in Norway (see Table 1) and the data were downloaded from the Coriolis data center (http://www.coriolis.eu.org/). Irradiance measurements imposed the float to emerge from the sea around local noon. Consequently, the chlorophyll fluorescence surface values were affected by non-photochemical quenching. For that reason, the chlorophyll observations made by this float were not used to investigate the Nordic Seas bloom onsets.

The IMR9 float was a PROVOR profiler equipped with a Satlantic OC4 radiometer measuring downwelling irradiance at 380, 412, and $490 \mathrm{~nm}$ and Photosynthetically Available Radiation (PAR) integrated between 400 and $700 \mathrm{~nm}$, a WET Labs ECO triplet comprising a chlorophyll fluorometer, a backscattering sensor at two wavelengths (532 and $700 \mathrm{~nm})$ and an Aanderaa optode $\left[\mathrm{O}_{2}\right]$ sensor. The IMR9 float nominal mission included CTD and bio-optical profiles from $1000 \mathrm{~m}$ to the surface. The optical and CTD sampling resolution was $1 \mathrm{~m}$. The upward casts were repeated every 5 days. The floats emerged from the sea around local noon.
The performance of the irradiance model was evaluated using 238 observations of iPAR just beneath the sea surface at local noon $\left[\mathrm{iPAR}_{\text {float }}(0, t=\right.$ noon $\left.)\right]$ made by the float IMR9. Theoretical iPAR values $\left[\operatorname{iPAR}_{\text {model }}(0, t=\right.$ noon $\left.)\right]$ were estimated using Eq. (2) for the same location and time of the day than the measurements. Four statistical indicators were used to evaluate the performance of the model. The first three indicators are relative to the least square regression fitted within the log-transformed data (to account for $\operatorname{iPAR}_{\text {float }}(0, t=$ noon $)$ ranging over 3 orders of magnitude and being lognormally distributed): the coefficient of determination $r^{2}$, slope and intercept. We also computed the coefficient of variation, $\sqrt{e^{\left(\sigma^{2}\right)}-1}$, where $\sigma^{2}$ is the variance of the log-transformed data. Overall, the iPAR estimates are in good agreement with the iPAR observations with a slope of 0.82 , a positive intercept of 1.57 and a coefficient of determination $r^{2}$ of 0.72 . However, with a coefficient of variation of 1.30 compared to 1.38 for the observations, the model reproduces a lower variability due to cloud coverage than the data (see Fig. S12). 


\section{Appendix B: Calculation of the photoperiod}

The photoperiod is the time spent by a cell in the euphotic layer within 1 day. In the open ocean this time depends on the length of daytime, the thickness of the euphotic layer and the trajectories of a cell in the turbulent mixed layer. The estimation of the euphotic layer depth and the calculation of the cell trajectories are discussed below.

\section{B1 Calculation of the euphotic layer depth}

The daily-averaged euphotic layer depth $\left(H_{\text {eu }}\right)$, defined as depth below which the light level is too low to support photosynthesis, was calculated by averaging Eq. (5) over the length of the day. In our data set, the winter euphotic layer depths were in the range of 150 to $170 \mathrm{~m}$ with a mean value of $165 \mathrm{~m}$. In the following calculations, the mean value across all 9 years is used as representative of the winter euphotic layer depth.

\section{B2 Calculation of the turbulent velocity in a convective mixed layer}

Mixed layer turbulence can be driven by heat fluxes, freshwater fluxes or winds. In the North Atlantic away from coastal regions, upper ocean turbulence is generated by the surface heat with minor contributions from freshwater fluxes and winds (Ferrari et al., 2014). Hence the analysis will focus on mixed layers forced by heat fluxes.

The root mean square vertical velocity in a mixed layer forced by thermal convection in a nonrotating environment follows a scaling verified by numerous laboratory experiments (Deardorff and Willis, 1985; Fernando et al., 1991), and numerical simulations (Deardorf, 1972; Molemaker and Dijkstra, 1997),

$w_{\mathrm{rms}}=A\left|B_{0} H\right|^{1 / 3}$,

where $H$ is the mixing layer depth, i.e the depth to which mixing penetrates (or equivalently the mixed layer depth, since mixing typically extends to the whole mixed layer during winter convection). $B_{0}$ is the surface buoyancy flux, and $A$ is a coefficient of proportionality. When the surface density is only affected by temperatures changes, $B_{0}$ can be related to the surface heat flux $B_{0}=\alpha g Q_{0} /\left(c_{\mathrm{P}} \rho_{0}\right)$, where $c_{\mathrm{P}}$ is the heat capacity, $\alpha$ is the thermal expansion coefficient, $\rho_{0}$ is the water density, and $g$ is the gravitational acceleration.

D'Asaro and collaborators (D'Asaro, 2001, 2008; Steffen and D'Asaro, 2002; Tseng and D'Asaro, 2004) using trajectories of Lagrangian floats have shown that the scaling (Eq. B1) applies also to winter convection in the real ocean. In particular Steffen and D'Asaro (2002) found that Eq. (B1) applies to convection in the North Atlantic with a coefficient A in the range 0.3-0.6. In the following calculations we will set $A=0.45 \pm 0.15$.

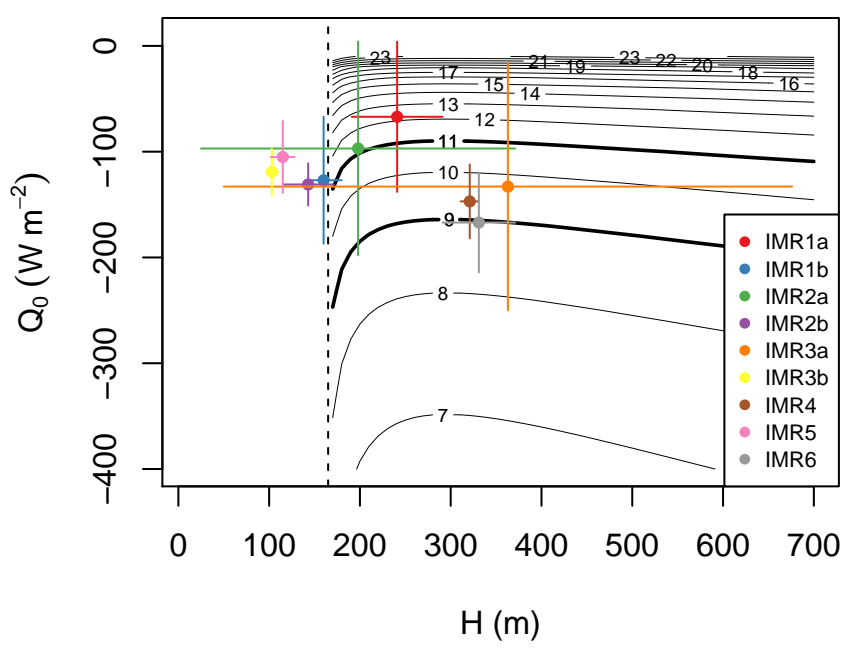

Figure B1. Residency time in the euphotic layer $\left(T_{\mathrm{eu}}\right)$ as a function of the ML depth $(H)$ and the surface heat flux $\left(Q_{0}\right)$ at the onset time of the bloom. The estimates are based on Eq. (B5) with the following parameter values: $A=0.45, c_{\mathrm{P}}=3984 \mathrm{~J}\left(\mathrm{~kg}^{\circ} \mathrm{C}\right)^{-1}, \alpha=$ $1.22 \times 10^{-4}{ }^{\circ} \mathrm{C}^{-1}, g=9.81 \mathrm{~m}^{2} \mathrm{~s}^{-1}, \rho_{0}=1028 \mathrm{~kg} \mathrm{~m}^{-3},\left(c_{\mathrm{P}}, \alpha\right.$ and $\rho_{0}$ are the average values at the nine bloom onsets). The vertical dashed line is the euphotic depth, $H_{\mathrm{eu}}=165 \mathrm{~m}$. The dots represent the ML depth and surface heat flux at bloom onset for all floats. The estimates for $Q_{0}, \mathrm{H}$ and their uncertainties are discussed in the text.

\section{B3 Calculation of the cell residence time in the euphotic layer during a convection event}

Armed with estimates of the euphotic layer depth and the magnitude of the turbulent velocity, we can now estimate the fraction of time that a particle spends in the euphotic layer during convection. We idealize the looping trajectories in turbulent convective cells as periodic oscillations between the ocean surface and the ML depth $H$,

$z(t)=\frac{H}{2}[\cos (\Omega t)-1]$,

where $T=2 \pi / \Omega$ is the period of the oscillations. The assumption of well-defined orbits is an approximation and real trajectories will be more variable. The vertical velocity of the particles is therefore given by

$w=\frac{\mathrm{d} z}{\mathrm{~d} t}=-\frac{1}{2} H \Omega \sin (\Omega t)$.

Averaging $w^{2}$ over a period, we obtain the root mean square velocity, $w_{\text {rms }}=\frac{1}{2 \sqrt{2}} H \Omega$. This expression, together with the scaling law for $w_{\text {rms }}$, in Eq. (B1), gives a scaling law for the frequency $\Omega$ and the period $T$ of the oscillations in the mixed layer,

$\Omega=\frac{2 \sqrt{2} A\left|B_{0} H\right|^{1 / 3}}{H}$ and $T=\frac{\pi H}{\sqrt{2} A\left|B_{0} H\right|^{1 / 3}}$.

To assess the skill of the scaling for $T$, we compared the prediction of $T$ from Eq. (B4) with two estimates of the 
overturning timescale from Lagrangian floats deployed in the North Atlantic (Steffen and D'Asaro, 2002). The results are reported in Table C1. Equation (B4) predicts overturning timescales of $1.5 \pm 0.6$ and $1.3 \pm 0.5$ days using the observed mixed layer depths and heat fluxes in good agreement with float-based estimates of 1.2 and 1.6 days respectively.

The residency time of particles in the euphotic layer is now easily computed as the time a particle spends between the surface and the euphotic layer depth $H_{\mathrm{eu}}$. Assuming that the overturning timescale $T$ is longer than the length of daytime, then the particles will visit the euphotic layer only once per day for a period of time given by

$T_{\mathrm{eu}}=\frac{H \operatorname{arcos}\left(1-2 H_{\mathrm{eu}} / H\right)}{\sqrt{2} A\left|B_{0} H\right|^{1 / 3}}$.

Figure B1 plots the residency time $T_{\mathrm{eu}}$ as a function of ML depth and heat flux, for the typical euphotic depth during winter in the region considered, $H_{\mathrm{eu}}=165 \mathrm{~m}$. For MLDs close to the euphotic depth, the particle speed is slow enough that cells in the euphotic layer experience light most of the daytime. For MLDs deeper than $200 \mathrm{~m}$, the time spent in the euphotic layer decreases with increasing heat flux and is very weakly dependent on the ML depth. One can understand this dependence taking the limit of Eq. (B5) for $H_{\mathrm{eu}} / H \ll 1$,

$T_{\mathrm{eu}} \sim \frac{\sqrt{2} H_{\mathrm{eu}}^{1 / 2} H^{1 / 6}}{A\left|B_{0}\right|^{1 / 3}}$.

The increase in $w_{\text {rms }}$ for increasing $H$ is offset by the decrease in speed close to the surface resulting in a weak dependence on $H$.

The residency time of phytoplankton cells in the upper $165 \mathrm{~m}$ at the onset of all nine blooms is shown in Fig. B1. The surface heat flux was estimated as the median value of $Q_{0}$ in the time interval between the last profile before $t_{\mathrm{E}}$ and the profile at $t_{\mathrm{E}}$. Its uncertainty was defined as the semiinterquartile range of $Q_{0}$ in the same time interval. For most blooms, $H$ was estimated as the average ML depth between the last profile before $t_{\mathrm{E}}$ and the profile at $t_{\mathrm{E}}$. The uncertainty in $H$ was set equal to the difference in ML depth between the last profile before $t_{\mathrm{E}}$ and the profile at $t_{\mathrm{E}}$. For the blooms IMR3 2010-2011 and IMR3 2011-2012, the [Chl $a$ ] was observed to increase in a layer shallower than the densitybased estimate of the ML depth. The mixed-layer depth is a poor estimator of the mixing layer depth as it may miss any slight restratification near the surface and it may also record past deeper mixing events. For these two blooms, it is therefore more appropriate to estimate $H$ as the depth of the layer where we observed an increase of [Chl $a$ ], which likely tracks the region where mixing was active.

Figure B1 shows that $H$ was shallower than $H_{\mathrm{eu}}$ at $t_{\mathrm{E}}$ of four of the blooms and therefore the cells remained in the euphotic layer for the whole length of daytime. For the remaining three floats, the cell residency time in the upper $165 \mathrm{~m}$ at $t_{\mathrm{E}}$ is estimated to have been longer than or equal to $9 \mathrm{~h}$.

\section{B4 Calculation of the photoperiod}

The photoperiod is the number of hours for which phytoplankton cells are exposed to sustained light during the day, i.e, the daily time spent in the euphotic layer. If the residency time $T_{\text {eu }}$ is longer than the day length or the $\mathrm{ML}$ is shallower than the euphotic depth, then the photoperiod for cells in the euphotic layer is equal to the day length; otherwise the photoperiod is shorter and equal to $T_{\mathrm{eu}}$. The Table C2 summarizes the day length, $H, Q_{0}$ and our estimate of $T_{\text {eu }}$ at each bloom onset.

In seven blooms, $t_{\mathrm{E}}$ occurred when the day length was between 9 and $11 \mathrm{~h}$ (Table C2). During that period, the surface heat losses remained smaller than $200 \mathrm{~W} \mathrm{~m}^{-2}$. For heat fluxes of this magnitude, cells spent more than $9 \mathrm{~h}$ in the upper $165 \mathrm{~m}$ as per Fig. B1, while the day length was shorter. Hence the photoperiod was equal to the day length and was between 9 and $11 \mathrm{~h}$ on the day of $t_{\mathrm{E}}$. The $2 \mathrm{~h}$ spread in photoperiod values most likely stems from the 10 day sampling of the floats, which is equivalent to a $1 \mathrm{~h}$ change in day length at the latitudes sampled by the floats. We conclude that the critical photoperiod when phytoplankton cells germinate is $10 \mathrm{~h}$ with an uncertainty of $1 \mathrm{~h}$ for these seven bloom events.

In the remaining two float years, $t_{\mathrm{E}}$ occurred when the day length was around $14 \mathrm{~h}$ (Table C2). The two floats were within $30 \mathrm{~km}$ of each other at bloom onset, so the two events are not really independent. In both cases, the heat losses were constantly above $200 \mathrm{~W} \mathrm{~m}^{-2}$ as the day length increased from 9 to $14 \mathrm{~h}$, as can be seen in Fig. 4 a looking at the 40 days prior to bloom onset. According to Fig. B1, such a strong heat flux generated enough mixing to prevent cells from experiencing more than $8 \mathrm{~h}$ of light. Thus, from the point of view of the cells, the photoperiod did not exceed $10 \mathrm{~h}$ until the surface heat fluxes decreased at the end of March and the day length was already $14 \mathrm{~h}$. We conclude that the bloom onset is consistent with a $10 \mathrm{~h}$ critical photoperiod for these two blooms as well. 


\section{Appendix C}

Table C1. Surface heat flux $Q_{0}$, ML depth $H$, and observed overturning time $T_{\mathrm{obs}}$ as reported in (Steffen and D'Asaro, 2002). The corresponding predicted overturning time $T_{\text {mod }}$ is based on Eq. (B4) with the following parameters: $A=0.45 \pm 15, c_{\mathrm{P}}=$ $3986 \mathrm{~J}\left(\mathrm{~kg}^{\circ} \mathrm{C}\right)^{-1}, \quad \alpha=8.98 \times 10^{-5}{ }^{\circ} \mathrm{C}^{-1}, g=9.81 \mathrm{~m}^{2} \mathrm{~s}^{-1}$, and $\rho_{0}=1027.764 \mathrm{~kg} \mathrm{~m}^{-3}$ derived from the observed salinity and potential temperature at the sea surface in (Steffen and D'Asaro, 2002). The $T_{\bmod }$ uncertainties $\left(\delta T_{\bmod }\right)$ are calculated as: $\delta T_{\bmod }=$ $\sqrt{\left(\partial T_{\bmod } / \partial A\right)^{2} \times \delta A^{2}+\left(\partial T_{\bmod } / \partial H\right)^{2} \times \delta H^{2}+\left(\partial T_{\bmod } / \partial Q_{0}\right)^{2} \times \delta Q_{0}^{2}}$, with $\delta A, \delta H$, and $Q_{0}$ being the uncertainties of $A, H$, and $Q_{0}$.

\begin{tabular}{lrr}
\hline & 1997 & 1998 \\
\hline$Q_{0}\left(\mathrm{~W} \mathrm{~m}^{-2}\right)$ & $270 \pm 40$ & $150 \pm 30$ \\
$H(\mathrm{~m})$ & $960 \pm 30$ & $630 \pm 20$ \\
$T_{\text {obs }}($ days $)$ & 1.2 & 1.6 \\
$T_{\text {mod }}$ (days $)$ & $1.5 \pm 0.6$ & $1.3 \pm 0.5$ \\
\hline
\end{tabular}

Table C2. Time of "emergence from noise" $t_{\mathrm{E}}$ (year-day), day length (h), ML depth $H(\mathrm{~m})$, surface heat flux $Q_{0}\left(\mathrm{~W} \mathrm{~m}^{-2}\right)$, the euphotic layer residency time $T_{\mathrm{eu}}$ and photoperiod at $t_{\mathrm{E}}(\mathrm{h})$. The day length is the estimated value at $t_{\mathrm{E}}$. The estimates for $Q_{0}, H$, and their uncertainty are discussed in the text. The estimates of $T_{\mathrm{eu}}$, based on Eq. (B5), are only indicated if $H>H_{\mathrm{eu}}=165 \mathrm{~m}$.

\begin{tabular}{llrrrrr}
\hline Bloom & $\begin{array}{l}t_{\mathrm{E}} \\
\text { (year-day) }\end{array}$ & $\begin{array}{r}\text { Day length } \\
(\mathrm{h})\end{array}$ & $\begin{array}{r}H \\
(\mathrm{~m})\end{array}$ & $\begin{array}{r}Q_{0} \\
\left(\mathrm{~W} \mathrm{~m}^{-2}\right)\end{array}$ & $\begin{array}{r}T_{\mathrm{eu}} \\
(\mathrm{h})\end{array}$ & $\begin{array}{r}\text { Photoperiod } \\
(\mathrm{h})\end{array}$ \\
\hline IMR1 2010-2011 (IMR1a) & 62 & 10 & $240 \pm 50$ & $-65 \pm 70$ & 12 & 10 \\
IMR1 2011-2012 (IMR1b) & 59 & 10 & $160 \pm 20$ & $-130 \pm 60$ & & 10 \\
IMR2 2010-2011 (IMR2a) & 96 & 14 & $200 \pm 170$ & $-100 \pm 100$ & 11 & 11 \\
IMR2 2011-2012 (IMR2b) & 70 & 11 & $140 \pm 30$ & $-130 \pm 20$ & & 11 \\
IMR3 2010-2011 (IMR3a) & 95 & 14 & $360 \pm 310$ & $-130 \pm 120$ & 10 & 10 \\
IMR3 2011-2012 (IMR3b) & 69 & 11 & $100 \pm 10$ & $-120 \pm 20$ & & 10 \\
IMR4 2014-2015 (IMR4) & 69 & 11 & $320 \pm 10$ & $-150 \pm 40$ & 10 & \\
IMR5 2014-2015 (IMR5) & 66 & 10 & $120 \pm 10$ & $-100 \pm 30$ & & \\
IMR6 2014-2015 (IMR6) & 72 & 11 & $330 \pm 40$ & $-170 \pm 50$ & 9 & 9 \\
\hline
\end{tabular}




\section{The Supplement related to this article is available online at doi:10.5194/bg-13-3485-2016-supplement.}

Acknowledgements. Alexandre Mignot and Raffaele Ferrari acknowledge NSF support through award OCE-1155205. This paper represents a contribution to the E-AIMS projects, which is funded by the European Research Council (grant agreement no. 312642). We thank the crew of the various cruises who deployed the Bio-optical floats used in the present study. We acknowledge many insightful conversations with Herve Claustre, Glenn Flierl, Emmanuel Boss and Mike Behrenfeld. We also thank four anonymous reviewers for many helpful comments and suggestions.

Edited by: E. Marañón

\section{References}

Antoine, D. and Morel, A.: Oceanic primary production: 1. Adaptation of a spectral light-photosynthesis model in view of application to satellite chlorophyll observations, Global Biogeochem. Cy., 10, 43-55, doi:10.1029/95GB02831, 1996.

Behrenfeld, M. J.: Abandoning Sverdrup's Critical Depth Hypothesis on phytoplankton blooms, Ecology, 91, 977-989, 2010.

Behrenfeld, M. J.: Climate-mediated dance of the plankton, Nature Climate Change, 4, 880-887, 2014.

Behrenfeld, M. J., Doney, S. C., Lima, I., Boss, E. S., and Siegel, D. A.: Annual cycles of ecological disturbance and recovery underlying the subarctic Atlantic spring plankton bloom, Global Biogeochem. Cy., 27, 526-540, 2013.

Bissinger, J. E., Montagnes, D. J. S., Sharples, J., and Atkinson, D.: Predicting marine phytoplankton maximum growth rates from temperature: Improving on the Eppley curve using quantile regression, Limnol. Oceanogr., 53, 487-493, 2008.

Boss, E., Swift, D., Taylor, L., Brickley, P., Zaneveld, R., Riser, S., Perry, M. J., and Strutton, P. G.: Observations of pigment and particle distributions in the western North Atlantic from an autonomous float and ocean color satellite, Limnol. Oceanogr., 53, 2112-2122, 2008.

Brainerd, K. and Gregg, M.: Surface Mixed and Mixing Layer Depths, Deep-Sea Res.-Oceanogr., 42, 1521-1543, 1995.

Budyko, M. I. and Donehoo, I. A.: Akademiiañauk SSSR and Mezhduvedomstvennyı̆ geofizicheskiı̆ komitet: Guide to the atlas of the heat balance of the earth: (atlas teplovogo balansa zemnogo shara), US Dept. of Commerce, Weather Bureau, Washington, DC, 1964.

Carval, T., Keeley, R., Takatsuki, Y., Yoshida, T., Schmid, C., Goldsmith, R., Wong, A., Thresher, A., Tran, A., Loch, S., and Mccreadie, R.: Argo user's manual V3.2, doi:10.13155/29825, 2015.

D'Asaro, E. A.: Turbulent vertical kinetic energy in the ocean mixed layer, J. Phys. Oceanogr., 31, 3530-3537, 2001.

D'Asaro, E. A.: Convection and the seeding of the North Atlantic bloom, J. Marine Syst., 69, 233-237, 2008.

Deardorf, J.: Numerical Investigation of Neutral and Unstable Planetary Boundary-Layers, J. Atmos. Sci., 29, 91-115, 1972.
Deardorff, J. and Willis, G.: Further Results from a Laboratory Model of the Convective Planetary Boundary-Layer, Bound.Lay. Meteorol., 32, 205-236, 1985.

Dee, D. P., Uppala, S. M., Simmons, A. J., Berrisford, P., Poli, P., Kobayashi, S., Andrae, U., Balmaseda, M. A., Balsamo, G., Bauer, P., Bechtold, P., Beljaars, A. C. M., van de Berg, L., Bidlot, J., Bormann, N., Delsol, C., Dragani, R., Fuentes, M., Geer, A. J., Haimberger, L., Healy, S. B., Hersbach, H., Holm, E. V., Isaksen, L., Kallberg, P., Koehler, M., Matricardi, M., McNally, A. P., Monge-Sanz, B. M., Morcrette, J.-J., Park, B.-K., Peubey, C., de Rosnay, P., Tavolato, C., Thepaut, J.-N., and Vitart, F.: The ERA-Interim reanalysis: configuration and performance of the data assimilation system, Q. J. R. Meteorol. Soc., 137, 553-597, 2011.

Degerlund, M. and Eilertsen, H. C.: Main Species Characteristics of Phytoplankton Spring Blooms in NE Atlantic and Arctic Waters $\left(68-80^{\circ} \mathrm{N}\right)$, Estuaries Coasts, 33, 242-269, 2010.

Dutkiewicz, S., Hickman, A. E., Jahn, O., Gregg, W. W., Mouw, C. B., and Follows, M. J.: Capturing optically important constituents and properties in a marine biogeochemical and ecosystem model, Biogeosciences, 12, 4447-4481, doi:10.5194/bg-124447-2015, 2015.

Eilertsen, H. and Wyatt, T.: Phytoplankton models and life history strategies, South Afr. J. Marine Sci., 22, 323-338, 2000.

Eilertsen, H., Sandberg, S., and Tollefsen, H.: Photoperiodic Control of Diatom Spore Growth - a Theory to Explain the Onset of Phytoplankton Blooms, Mar. Ecol. Prog. Ser., 116, 303-307, 1995.

Evans, G. T. and Parslow, J. S.: A Model of Annual Plankton Cycles, Biol. Oceanogr., 3, 327-347, 1985.

Fernando, H., Chen, R., and Boyer, D.: Effects of Rotation on Convective Turbulence, J. Fluid Mech., 228, 513-547, 1991.

Ferrari, R., Merrifield, S. T., and Taylor, J. R.: Shutdown of convection triggers increase of surface chlorophyll, J. Marine Syst., 147, 116-122, doi:10.1016/j.jmarsys.2014.02.009, 2014.

Forsythe, W., Rykiel, E., Stahl, R., Wu, H., and Schoolfield, R.: A Model Comparison for Daylength as a Function of Latitude and Day of Year, Ecol. Model., 80, 87-95, 1995.

Geider, R., Osborne, B., and Raven, J.: Growth, Photosynthesis and Maintenance Metabolic Cost in the Diatom PhaeodactylumTricornutum at Very Low Light Levels, J. Phycol., 22, 39-48, 1986.

Gran, H. H. and Braarud, T.: A Quantitative Study of the Phytoplankton in the Bay of Fundy and the Gulf of Maine (including Observations on Hydrography, Chemistry and Turbidity), J. Biol. Board Can., 1, 279-467, 1935.

Gregg, W. and Carder, K.: A Simple Spectral Solar Irradiance Model for Cloudless Maritime Atmospheres, Limnol. Oceanogr., 35, 1657-1675, 1990.

Hamner, K. C.: Interrelation of Light and Darkness in Photoperiodic Induction, Bot. Gaz., 101, 658-687, 1940.

Hamner, K. C. and Bonner, J.: Photoperiodism in Relation to Hormones as Factors in Floral Initiation and Development, Bot Gaz., 100, 388-431, 1938.

Kara, A. B., Rochford, P. A., and Hurlburt, H. E.: An optimal definition for ocean mixed layer depth, J. Geophys. Res.-Ocean., 105, 16803-16821, 2000. 
Kara, A. B., Rochford, P. A., and Hurlburt, H. E.: Mixed layer depth variability over the global ocean, J. Geophys. Res.-Ocean., 108, 3079-3094, doi:10.1029/2000JC000736, 2003.

Koeller, P., Fuentes-Yaco, C., Platt, T., Sathyendranath, S., Richards, A., Ouellet, P., Orr, D., Skuladottir, U., Wieland, K., Savard, L., and Aschan, M.: Basin-Scale Coherence in Phenology of Shrimps and Phytoplankton in the North Atlantic Ocean, Science, 324, 791-793, 2009.

McMinn, A. and Martin, A.: Dark survival in a warming world, Proc. Biol. Sci., 280, 20122909, doi:10.1098/rspb.2012.2909, 2013.

Molemaker, M. J. and Dijkstra, H. A.: The formation and evolution of a diffusive interface, J. Fluid Mech., 331, 199-229, 1997.

Moore, J. K., Doney, S. C., Kleypas, J. A., Glover, D. M., and Fung, I. Y.: An intermediate complexity marine ecosystem model for the global domain, Deep-Sea Res. Pt. I, 49, 403-462, 2002.

Morel, A., Huot, Y., Gentili, B., Werdell, P. J., Hooker, S. B., and Franz, B. A.: Examining the consistency of products derived from various ocean color sensors in open ocean (Case 1) waters in the perspective of a multi-sensor approach, Remote Sens. Environ., 111, 69-88, 2007.

Platt, T., Fuentes-Yaco, C., and Frank, K. T.: Spring algal bloom and larval fish survival, Nature, 423, 398-399, 2003.

R Development Core Team: R Development Core Team: A language and environment for statistical computing. R Foundation for Statistical Computing, Vienna, Austria. ISBN 3-900051-070, http://www.R-project.org (last access: 1 May 2016), 2016.

Riley, G.: Factors Controlling Phytoplankton Populations on Georges Bank, J. Mar. Res., 6, 54-73, 1946.

Skjelvan, I., Olsen, A., Anderson, L. G., Bellerby, R. G. J., Falck, E., Kasajima, Y., Kivimäe, C., Omar, A., Rey, F., Olsson, K. A., Johannessen, T., and Heinze, C.: A review of the inorganic carbon cycle of the Nordic Seas and Barents Sea, in: Geophysical Monograph Series, edited by: Drange, H., Dokken, T., Furevik, T., Gerdes, R., and Berger, W., American Geophysical Union, Washington, DC, 158, 157-175, available from: http://www.agu. org/books/gm/v158/158GM11/158GM11.shtml (last access: 25 April 2014), 2005.
Smith, R. and Baker, K.: Optical-Properties of the Clearest NaturalWaters (200-800 Nm), Appl. Opt., 20, 177-184, 1981.

Steffen, E. L. and D'Asaro, E. A.: Deep convection in the Labrador Sea as observed by Lagrangian floats, J. Phys. Oceanogr., 32, 475-492, 2002.

Sverdrup, H. U.: On Conditions for the Vernal Blooming of Phytoplankton, J. Cons., 18, 287-295, 1953.

Takahashi, T., Sutherland, S. C., Sweeney, C., Poisson, A., Metzl, N., Tilbrook, B., Bates, N., Wanninkhof, R., Feely, R. A., Sabine, C., Olafsson, J., and Nojiri, Y.: Global sea-air $\mathrm{CO}_{2}$ flux based on climatological surface ocean $p \mathrm{CO}$, and seasonal biological and temperature effects, Deep-Sea Res. Pt. I, 49, 1601-1622, 2002.

Tseng, R. S. and D'Asaro, E. A.: Measurements of turbulent vertical kinetic energy in the ocean mixed layer from Lagrangian floats, J. Phys. Oceanogr., 34, 1984-1990, 2004.

Wong, A., Keeley, R., Carval, T., and the Argo Data Management Team: Argo quality control manual, Technical report, Argo Data Management team, 2010.

Xing, X., Claustre, H., Uitz, J., Mignot, A., Poteau, A., and Wang, H.: Seasonal variations of bio-optical properties and their interrelationships observed by Bio-Argo floats in the subpolar North Atlantic, J. Geophys. Res.-Oceans, 119, 7372-7388, doi:10.1002/2014JC010189, 2014. 